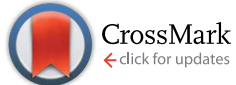

Cite this: Chem. Sci., 2015, 6, 2687

Received 24th January 2015

Accepted 5th March 2015

DOI: $10.1039 / \mathrm{c} 5 \mathrm{sc00280j}$

www.rsc.org/chemicalscience

\section{Stereocontrolled 1,2-cis glycosylation as the driving force of progress in synthetic carbohydrate chemistry}

\author{
Swati S. Nigudkar and Alexei V. Demchenko* \\ Recent developments in stereoselective 1,2-cis glycosylation that have emerged during the past decade are \\ surveyed herein. For detailed coverage of the previous achievements in the field the reader is referred to our \\ earlier reviews: A. V. Demchenko, Curr. Org. Chem., 2003, 7, 35-79 and Synlett, 2003, 1225-1240.
}

\section{A. Introduction}

Carbohydrates, as polysaccharides or glycoconjugates, represent the largest class of naturally occurring compounds that are often found as essential components of many bioactive molecules in nature. Carbohydrates were initially viewed as energystorage materials, structural components, and primary metabolites. Now it is known that carbohydrates mediate many fundamental biological processes such as immune defense, fertilization, metastasis, signal transduction, cell growth and cell-cell adhesion. In the past few years, we have been learning that carbohydrates play crucial roles in pathogenesis of diabetes, bacterial and viral infections, inflammation, development and growth of cancers, septicemia, and many other diseases. Clearly, uncovering the contributions of carbohydrates to cell biology would greatly facilitate advances in the field of glycosciences. ${ }^{1}$

For the most part, medicinally important carbohydrates exist as complex oligomers or as conjugates with other biomolecules including natural products, lipids, peptides, proteins, $e t c{ }^{2}$ The carbohydrate part itself exists in various sizes and shapes ranging from monomeric sugars and simple linear chains to highly branched glycoforms. Major obstacles in studying natural carbohydrates are the difficulties in isolating, characterizing, and synthesizing these molecules due to their low abundance and heterogeneity in nature. While scientists have been able to successfully isolate and characterize certain classes of natural carbohydrates, the availability of pure isolates is still low. As a consequence, the systematic study of these molecules often relies on synthetic chemistry to provide pure compounds in significant quantities.

Among the variety of glycosidic bonds in nature, it is the $O$-glycosidic bonds that are of major interest and challenge to chemists due to their high abundance and difficulty in synthesis. There are two major types of $O$-glycosides, which are, depending on nomenclature, most commonly defined as $\alpha$ - and $\beta$-, or 1,2-cis and 1,2-trans glycosides. Both 1,2-cis and 1,2-trans glycosides are important and abundant classes of linkages and are commonly found as components in a variety of natural compounds. However, it is 1,2-cis glycosyl residues, $\alpha$-glycosides for $\mathrm{D}$-glucose, $\mathrm{D}$-galactose or $\beta$-glycosides for $\mathrm{D}$-mannose, L-rhamnose, etc. that have proven to be synthetic hurdles for chemists. This review is dedicated to recent developments that have emerged to address the challenge of stereoselective 1,2-cis glycosylation. Some other common types of glycosides, for instance 2-deoxyglycosides and sialosides, lack the neighboring substituent. These compounds can neither be defined as 1,2-cis nor 1,2-trans glycosides, hence, these are commonly referred to as $\alpha$ - and $\beta$-glycosides. Representative examples of common glycosides are shown in Fig. 1.

Many oligosaccharides containing 1,2-cis O-glycosidic linkages are of high importance due to their biological roles and therapeutic potential. Some representative naturally occurring

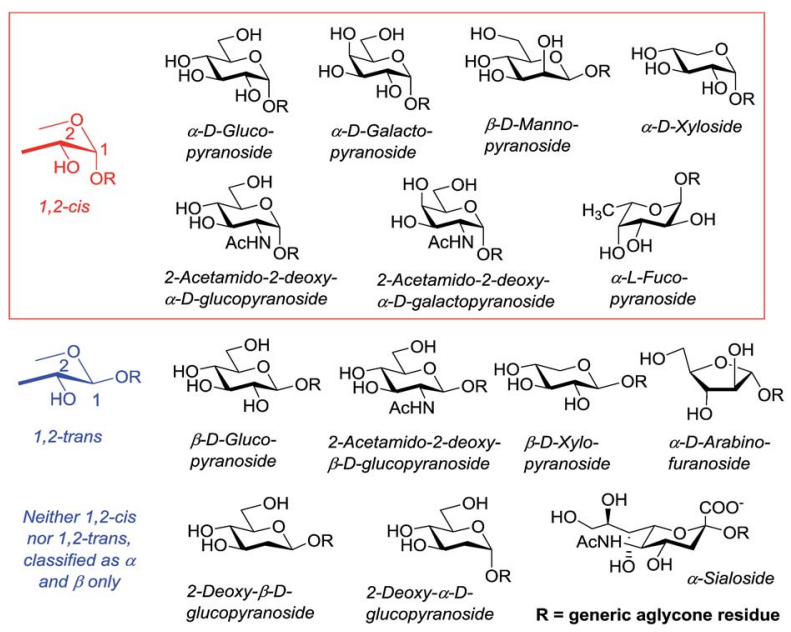

Fig. 1 Common monosaccharide residues found in the mammalian and bacterial glycome. 
oligosaccharides containing 1,2-cis linkages are shown in Fig. 2. For example, the immunomodulatory pentasaccharide FPS-1 from Aconitum carmichaeli is composed of an $\alpha-(1 \rightarrow 6)$-linked backbone with some $\alpha-(1 \rightarrow 3)$ branching. ${ }^{3}$ The fungus Pseudallescheria boydii consists of a glycogen-like $\alpha-(1 \rightarrow 4)$-linked glucan backbone with occasional $\alpha-(1 \rightarrow 6)$-glucosyl branches. ${ }^{4}$ The zwitterionic polysaccharide A1 found on the capsule of the bacterium Bacteroides fragilis has a 1,2-cis-linked glycosaminoglycan motif. ${ }^{5}$ Many pneumococcal polysaccharides possess 1,2-cis glycosidic linkages, for instance a polysaccharide from Streptococcus pneumonia serotype $6 \mathrm{~B}^{6}$ that is included in all current pneumococcal vaccines, has $\alpha$-glucosyl and $\alpha$-galactosyl residues. The trisaccharide repeating unit isolated from Staphylococcus aureus type $5^{7}$ possesses uncommon ManNAcA and FucNAc, both 1,2-cis-glycosidically linked. High mannose-type $N$-linked glycans ${ }^{8}$ that mediate the pathogenesis of many diseases bear an important 1,2-cis-linked $\beta$-mannosyl residue. All glycosphingolipids of the globoside family have an $\alpha$-linked galactosyl residue and Globo- $\mathrm{H}$, which is a current target for breast and prostate cancer vaccine development, ${ }^{9}$ has an $\alpha$-fucosyl residue as well.

\section{B. Outline of chemical glycosylation: mechanism, general principles and special cases}

Glycosylation is arguably the most important, albeit challenging, reaction in the field of carbohydrate chemistry. Most commonly, it involves the reaction between a glycosyl donor and glycosyl acceptor, in the presence of an activator or

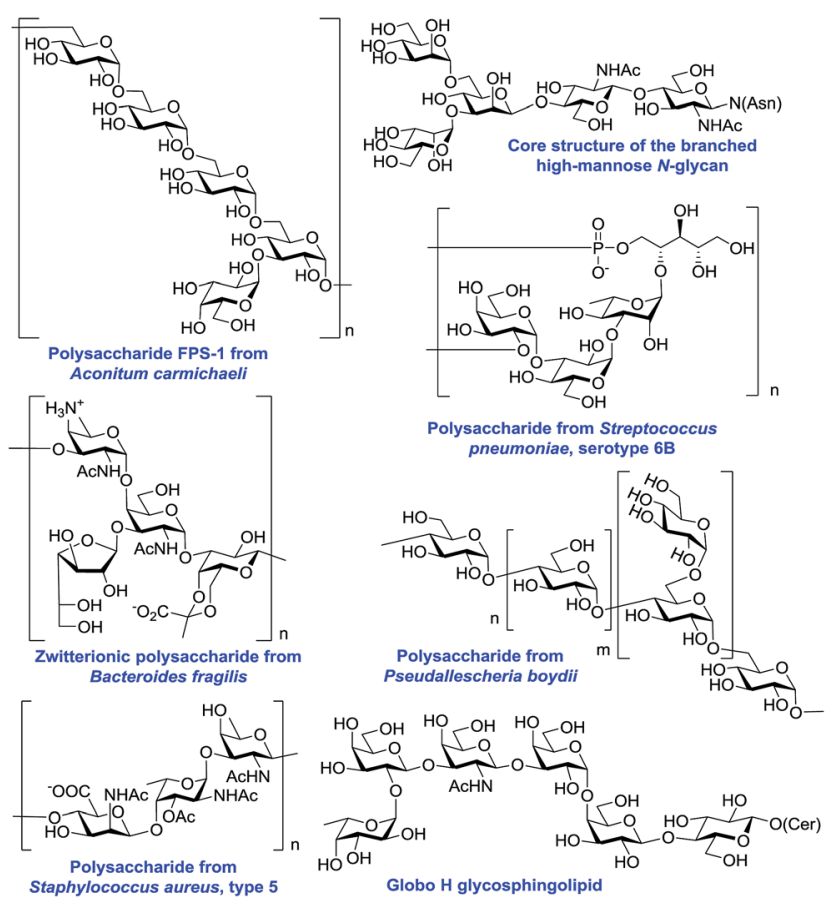

Fig. 2 Naturally occurring oligosaccharides containing 1,2-cis linkages. promoter, to form a glycosidic bond. Upon activation, the promoter-assisted departure of the leaving group results in the formation of a glycosyl cation, which then gets stabilized via an oxacarbenium ion intermediate (Scheme 1a). The nucleophile, glycosyl acceptor, can then attack (to form the glycosidic bond) either from the top or the bottom face of the flattened ring. This would give rise to either 1,2-trans or 1,2-cis glycosides with respect to the neighboring substituent at $\mathrm{C}-2$, and uncontrolled reactions may lead to a mixture thereof.

The formation of 1,2-trans linkages can be accomplished using the participatory effect of the neighboring 2-acyl substituent. In this case, the oxacarbenium ion can be further stabilized via a bicyclic acyloxonium intermediate, which becomes the key intermediate en route to glycosylation products (Scheme 1b). Since the bottom face of the ring is blocked, nucleophilic attack of the glycosyl acceptor would be directed from the opposite, top face. This typically provides access to the 1,2-trans linkage with very high or complete stereoselectivity. Occasionally, substantial amounts of 1,2-cis-linked products or orthoester formation are also observed.

While the stereoselective synthesis of 1,2-trans linkages can be reliably achieved with the use of neighboring group assistance, ${ }^{\mathbf{1 0}}$ the formation of 1,2 -cis linkages is typically much more challenging. The presence of a non-participating group is required for the synthesis of 1,2-cis glycosides, but the nonparticipating group alone cannot ensure the stereoselectivity. Although the $\alpha$-product is favored by the anomeric effect, ${ }^{11}$ the stereoselectivity of glycosylation can be poor and requires other modes of stereocontrol. A variety of reaction conditions and structural elements of the reactants has been investigated. Although there are many examples wherein excellent 1,2-cis
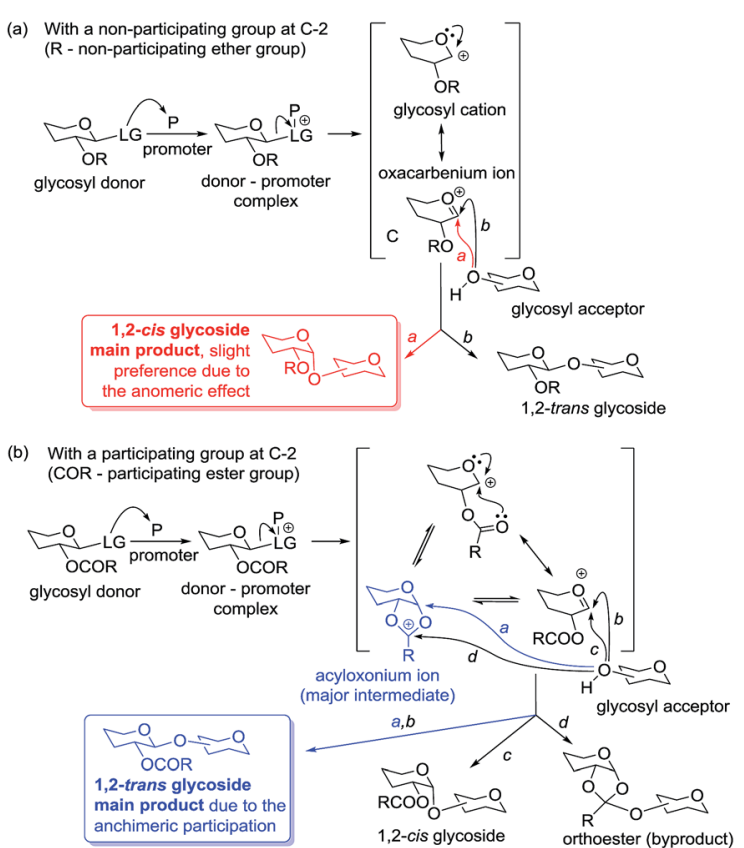

Scheme 1 General outline of glycosylation and the key intermediates involved. 
stereoselectivity of certain linkages has been achieved, no comprehensive method for 1,2-cis glycosylation is available. ${ }^{12}$

In addition to the apparent complexity of the glycosylation process, there are other competing processes that cannot be disregarded. Side reactions, such as elimination, substitution (formation of unexpected substitution products or hydrolysis at the anomeric center), cyclization (inter and intramolecular orthoesterification), migration, redox, etc., ${ }^{13}$ often complicate stereocontrol and compromise the yield of glycosylation. Several factors are known to affect the stereoselectivity and yield of glycosylation and those include temperature, solvent, type of donor used, type of acceptor used, amount and type of promoter used, protecting groups, etc. (Fig. 3). These effects and specifically designed methods to control the stereoselectivity of glycosylation will be discussed in the subsequent sections. While some sugars follow general trends, there are classes of compounds and glycosidic linkages that require special methods. These special cases of glycosylation require careful selection of techniques, their modification, or design of conceptually new approaches. Indirect or total synthesis-based technologies have been developed and applied specifically to the synthesis of these targets.

Glycosides of 2-amino-2-deoxy sugars, in particular those of the $\mathrm{D}$-gluco and D-galacto series, are widely distributed in living organisms as glycoconjugates or glycosaminoglycans. ${ }^{14}$ Since a vast majority of naturally-occurring 2-amino-2-deoxy sugars are $\mathrm{N}$-acetylated, from a synthetic point of view, a 2-acetamido-2deoxy substituted glycosyl donor would be desirable. For this type of glycosyl donor, however, the oxacarbenium ion rearranges rapidly into an unreactive oxazoline intermediate. Therefore, even the synthesis of such 1,2-trans glycosides requires additional steps and a careful selection of suitable protecting groups. A minimal requirement for the synthesis of 1,2-cis glycosides would be the use of a C-2 non-participating moiety, most commonly azide. 2,3-Oxazolidinone protection introduced by Kerns and $N$-p-methoxybenzylidene protection explored by Nguyen also show good promise to become universal approaches to 1,2-cis glycosylation with 2-aminosugars (vide infra).

$\beta$-Mannosyl residues are frequently found in glycoproteins. The chemical synthesis of $\beta$-mannosides cannot be achieved by relying on the anomeric effect, which would favor axial $\alpha$-mannosides. In addition, the formation of $\beta$-mannosides is further disfavored by the repulsive interactions that would have
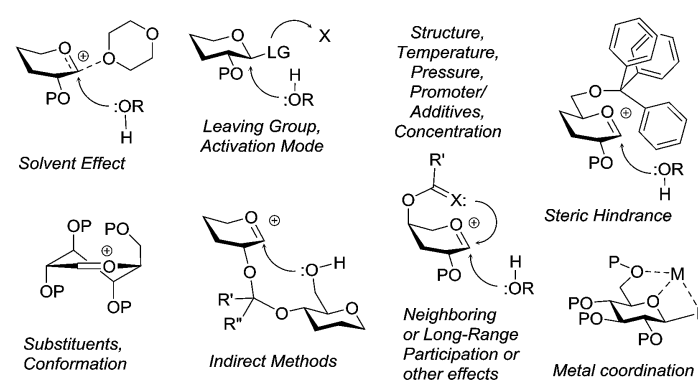

Steric Hindrance

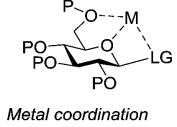

Fig. 3 Factors affecting stereoselectivity. occurred between the axial C-2 substituent and the nucleophile approaching from the top face of the ring. For many years, the only direct procedure applicable to $\beta$-mannosylation - Ag-silicate promoted glycosidation of $\alpha$-halides - was assumed to follow a bimolecular $\mathrm{S}_{\mathrm{N}} 2$ mechanism. ${ }^{15}$ The difficulty of direct $\beta$-mannosylation was addressed by developing a variety of indirect approaches such as C-2 oxidation-reduction, C-2 inversion, anomeric alkylation, and intramolecular aglycone delivery. ${ }^{16}$ This was the standing in the field before Crich and co-workers discovered that 4,6-O-benzylidene protected sulfoxide $^{17}$ or thioglycoside ${ }^{18}$ glycosyl donors provide excellent $\beta$-manno stereoselectivity. Detailed mechanistic and spectroscopic studies by the Crich group ${ }^{19}$ showed that anomeric $\alpha$-O-triflates generated in situ are reactive intermediates that can be converted into $\beta$-mannosides with high stereocontrol at low temperatures.

In comparison to their six-membered counterparts, furanosides are less abundant. Nevertheless, their presence in a variety of polysaccharides from plants, bacteria, parasites, and fungi makes this type of glycosidic linkage an important synthetic target. ${ }^{20}$ The synthesis of 1,2-trans furanosides is relatively straightforward and, similarly to that of pyranosides, can be reliably achieved with the use of glycosyl donors bearing a participating group at C-2. In contrast, the synthesis of 1,2-cis furanosides is difficult, even more so than with pyranosides due to the lack of anomeric effect and the conformational flexibility of the five-membered ring. In fact, both electronic and steric effects favor the formation of 1,2-trans furanosides. In the past decade, a notable improvement in 1,2-cis furanosylation was made possible with glycosyl donors in which the ring has been locked into a single conformation. These examples include 2,3-anhydro, ${ }^{21}$ 3,5-O-(di-tert-butylsilylene), ${ }^{22}$ and 3,5-O-tetraisopropyldisiloxanylidene ${ }^{23}$ protected bicyclic glycosyl donors. A recent example wherein stereoselective 1,2-cis glycofuranosylation was accomplished with the assistance of H-bond mediated aglycone delivery will be discussed below.

2-Deoxyglycosides are important constituents of many classes of antibiotics. The development of reliable methods for the stereoselective synthesis of both $\alpha$ - and $\beta$-2-deoxyglycosides is critical for the synthesis of natural products, drugs and glycomimetics. ${ }^{24}$ It should be noted that due to the lack of anchimeric assistance from the substituent at $\mathrm{C}-2$, the synthesis of both types of linkages represents a notable challenge. Direct glycosylation of 2-deoxy glycosyl donors often results in the formation of anomeric mixtures, though notable recent progress in the area has to be acknowledged..$^{25,25 g}$ In spite of extensive efforts and notable progress, the chemical synthesis of sialosides also remains a significant challenge. ${ }^{26}$ The presence of a destabilizing electron-withdrawing carboxylic group and the lack of a participating auxiliary often drive sialylation reactions toward competitive elimination reactions resulting in the formation of a 2,3-dehydro derivative and/or in poor stereoselectivity ( $\beta$-anomer). To overcome these problems, a variety of leaving groups and activation conditions for direct sialylation have been developed. It was also demonstrated that the $N$-substituent at C-5 plays an influential role in both the stereoselectivity of sialylation and the reactivity of sialyl donors. ${ }^{26 d} \mathrm{~A}$ 
particular advance in recent years has been made with 4,5- $\mathrm{O}, \mathrm{N}-$ oxazolidinone derivatives that provide high yields and stereoselectivities in sialylation. ${ }^{27}$

\section{Effect of the glycosyl donor}

Glycosylations using trichloroacetimidates (TCAI) ${ }^{28}$ and thioglycosides $^{29}$ as donors have become the most widely studied methods for chemical glycosylation. Our previous reviews on 1,2-cis glycosylation thoroughly discuss all pros and cons of using various leaving groups. ${ }^{12 a, 12 b}$ Since glycosylation reactions commonly follow a unimolecular $\mathrm{S}_{\mathrm{N}} 1$ displacement mechanism, the orientation of the leaving group at the anomeric center is of little importance. However, occasionally glycosylation reactions proceed via an $\mathrm{S}_{\mathrm{N}}$ 2-like mechanism with inversion of the anomeric configuration. The following leaving groups often provide excellent 1,2-cis selectivity: $\beta$-glycosyl halides formed from their $\alpha$-counterparts with bromonium ions $^{30}$ or from $\alpha$-thioglycosides in the presence of bromine, ${ }^{31}$ glycosyl thiocyanates, ${ }^{32}$ and anomeric mannosyl triflates formed in situ from sulfoxides or thioglycosides for the synthesis of $\beta$-mannosides. ${ }^{17,18}$

It is well known that the stereoselectivity of glycosylation can be profoundly influenced by protecting groups. ${ }^{33}$ Neighboring protecting groups at C-2 traditionally known as participating groups for the synthesis of 1,2-trans glycosides can now assist in the formation of either 1,2-cis or 1,2-trans glycosides. Remote protecting groups at positions C-3, 4 and/or 6 may affect the stereoselectivity by means of participation, $\mathrm{H}$-bond mediated aglycone delivery, steric hindrance and/or electron withdrawal. Also discussed in this section are protecting groups that restrict the conformational flexibility of carbohydrates or force carbohydrate molecules to adopt unusual conformations. Glycosidation of unprotected glycosyl donors with reactive glycosyl acceptors proceeding with good to excellent 1,2-cis stereoselectivity has also been reported. ${ }^{34}$

\section{C.1. Neighboring protecting group at $\mathrm{C}-2$}

As aforementioned, neighboring acyl-type protecting groups offer one of the most powerful tools to direct stereoselectivity toward the formation of a 1,2-trans-linked product. Demchenko and co-workers developed glycosyl donors equipped with a 2-picolinyl ether substituent that can also participate and form 1,2-trans glycosides stereoselectively. ${ }^{35}$ Boons and co-workers developed a participating group capable of participation from the opposite face of the ring giving rise to 1,2-cis linked glycosides. ${ }^{36}$ On activation of the glycosyl donor, the resulting oxacarbenium ion is attacked by a nucleophilic moiety via a sixmembered intermediate. This attack, in principle, can lead to the formation of a cis- or trans-decalin-like system, and Boons and co-workers showed that the selectivity is highly dependent on the configuration of the asymmetric center of the chiral protecting group. To accommodate the bulky phenyl group in the pseudo-equatorial position of the newly formed six-membered ring, an auxiliary with $(S)$-stereochemistry would favor the trans-decalin-like intermediate. As a result, the nucleophilic attack of the glycosyl acceptor will occur from the bottom face leading to 1,2-cis-linked glycosides. Conversely, a chiral auxiliary with the opposite $(R)$-configuration could participate via the cis-decalin-like intermediate, thereby producing 1,2-trans glycosides. Ethyl mandelate was chosen to test this methodology because both the enantiomers are readily available, the conditions required for its installation are compatible with other protecting groups, and it is stable during glycosylation, but can be readily removed under mild reductive conditions. As depicted in Scheme 2, when an ethyl (S)-mandelate-protected donor $(S)-\mathbf{1}$ was glycosidated with glycosyl acceptor $\mathbf{2}$, disaccharide 3 was obtained with high $\alpha$-selectivity $(\alpha / \beta=20 / 1)$. Conversely, when $(R)-\mathbf{1}$ was used as the glycosyl donor, a reversal of anomeric selectivity was observed $(\alpha / \beta=1 / 5)$. Deprotection of the acyl groups using sodium methoxide in methanol and benzyl groups, including the chiral auxiliary, under Birch reduction conditions provided disaccharide 4 .

The second generation auxiliary developed to further enhance 1,2-cis stereoselectivity was based on an (S)-phenylthiomethylbenzyl ether moiety at C-2 of the glycosyl donor. ${ }^{37}$ It was assumed that this type of moiety would be capable of more efficient and stereoselective participation via the formation of a chair and hence a more stable trans-decalin-like intermediate. In this case, the $(S)$-phenyl group will occupy the equatorial position to avoid unfavorable 1,3-diaxial interactions that would have occurred if the bulky phenyl group was placed in the axial position. As depicted in Scheme 3, 1-(S)-phenyl-2-(phenylsulfanyl)ethyl ether-protected TCAI donor 7 was obtained from glucose tetraacetate 5 via sequential protection, liberation of the anomeric hydroxyl and introduction of the imidoyl leaving group. Glycosyl donor 7 was then reacted with acceptor 8 in the presence of TMSOTf to afford $\alpha$-glycoside 9 in $86 \%$ yield and with exclusive $\alpha$-stereoselectivity. The auxiliary can then be removed by acetolysis in the presence of $\mathrm{BF}_{3}-\mathrm{OEt}_{2}$ and acetic anhydride. This method has been extended to the polymersupported synthesis of the repeating unit of the immunemodulatory polysaccharide from Aconitum carmichaeli composed of an $\alpha-(1 \rightarrow 6)$-linked glucosyl backbone branched with $\alpha-(1 \rightarrow 3)$-linked glucosyl moieties. ${ }^{38}$

More recently, to simplify this approach, Boons and co-workers adopted a different direction towards the synthesis of 1,2-cis glycosides. ${ }^{39}$ This was certainly inspired by their earlier work on chiral auxiliaries and inherent drawbacks related to the necessity of obtaining pure enantiomeric substrates. Additional

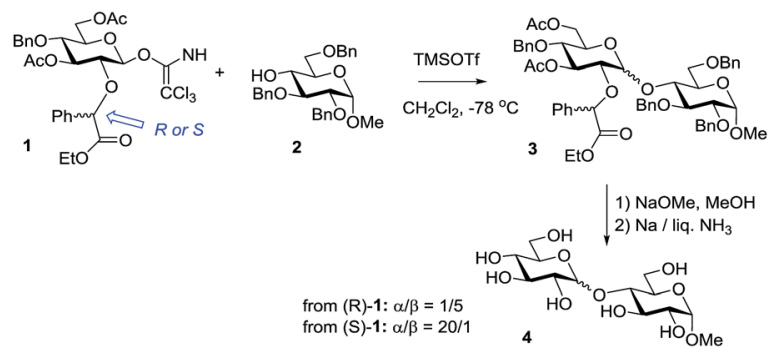

Scheme 2 Stereoselective glycosylation with ethyl $(R)$ - and $(S)$-mandelate protected glycosyl donor 1. 


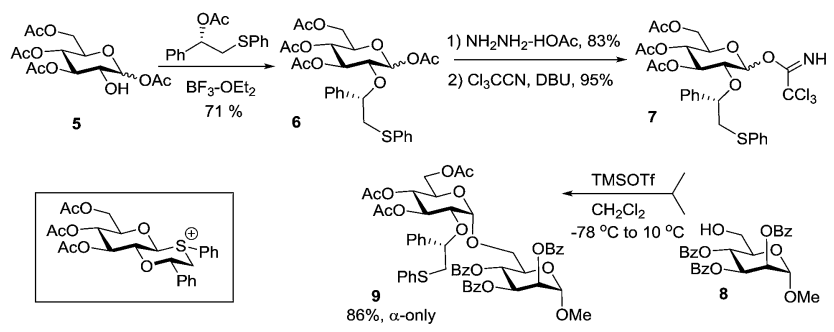

Scheme 3 Synthesis of C-2 (S)-phenyl-thiomethylbenzyl ether-protected glycosyl donor 6 and its glycosidation.

inspiration came from work by Turnbull $e t$ al. who developed a very elegant approach using thioglycoside donors $\mathbf{1 0}$ having an anomeric $\alpha$-directing group. ${ }^{40}$ As depicted in Scheme 4 a, these reactions proceeded via bicyclic intermediate $\mathbf{1 1}$ that was activated via oxidation into sulfoxide $\mathbf{1 2}$ and $S$-arylation to form reactive sulfonium ion 13 en route to $O$-glycoside 14.

In Boons' approach depicted in Scheme $4 \mathrm{~b},{ }^{39}$ sulfoxide donor 16 was prepared from thioglycoside $\mathbf{1 5}$ by treatment with trimethylsilyl anhydride $\left(\mathrm{TMS}_{2} \mathrm{O}\right)$ in the presence of TMSOTf, followed by reduction with $\mathrm{Et}_{3} \mathrm{SiH}$. Compound $\mathbf{1 6}$ was then subjected to a series of protecting group manipulations followed by oxidation with $m$-CPBA to give sulfoxide 17 . Glycosidation of donor 17 included treatment with trifluoromethanesulfonic anhydride $\left(\mathrm{Tf}_{2} \mathrm{O}\right)$, arylation with $1,3,5$ trimethoxybenzene, followed by the addition of glycosyl acceptors 18-20 to form the corresponding disaccharides 21-23 in high yields and stereoselectivities. ${ }^{39}$ It was observed that while the donors bearing electron-withdrawing groups at C-3, 4, and 6 gave only the $\alpha$-anomer, their 4,6-diether substituted counterparts suffered from a slight loss of $\alpha$-anomeric selectivity. This led to confusion that the highly reactive sulfonium ions partially react via the oxacarbenium ion intermediate.

Building upon their previous work, Turnbull and co-workers recently designed a new oxathiane donor scaffold where the axial methoxy group was replaced with an $O$-substituent constrained in a spirocyclic ring. ${ }^{41}$ As in the previous methods, the

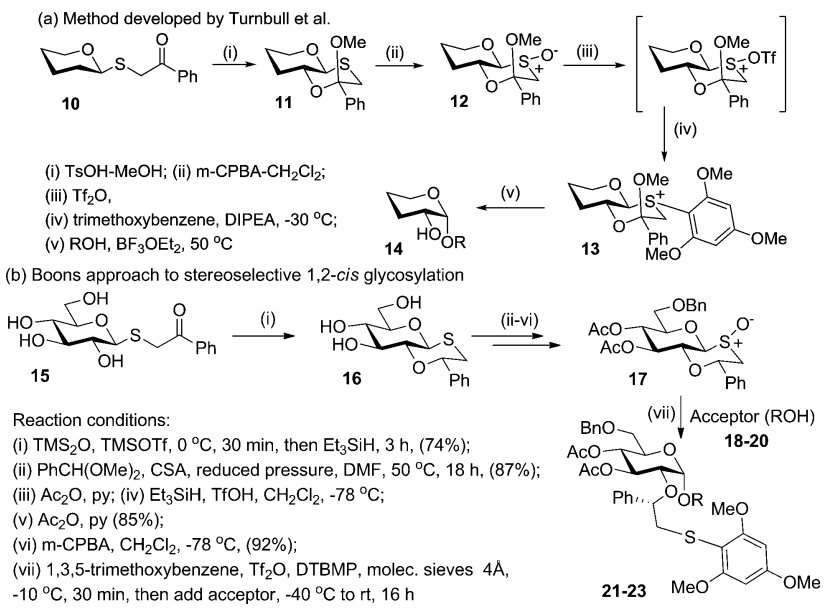

Scheme 4 Stereoselective glycosylation via sulfonium ions. oxathiane spiroketal donor is then activated via S-arylation. Overall, the novel class of oxathiane glycosyl donors is easily accessible, highly $\alpha$-selective in glycosylation, and offers high stability towards common protecting group manipulations.

\section{C.2. Remote protecting groups}

The effects of remote substituents have long been considered of somewhat lesser importance than those of the neighboring substituent at C-2. However, the idea of participating groups at remote positions has been brought to attention by many researchers. There have been various reports, starting from long-range 6-O-acyl or carbonate group assisted synthesis of $\alpha$-glucosides, ${ }^{42}$ both in favor and in opposition of the idea of remote participation. For derivatives of the D-galacto series a remote effect beneficial for the formation of $\alpha$-galactosides was also noted when a participating moiety was present at C-4. ${ }^{43}$ Similar effects (including C-3 participation) were also detected for the derivatives of the $\mathrm{L}$-fuco ${ }^{44} \mathrm{~L}$-rhamno, ${ }^{45} \mathrm{D}$-manno, ${ }^{46}$ and D-gluco ${ }^{47}$ series.

In 2009, Kim presented a dedicated study of the effect of 3and 6-O-acetyl donors on the stereoselectivity of mannosylation. ${ }^{48}$ The comparative study indicated remote participation by $3-O$ and 6-O acetyl groups, but showed no participation by the 4-O-acyl group. Thus, when mannopyranosyl TCAI donors bearing electron-withdrawing ester groups, such as acetyl (24) or benzoyl (25) at the C-3 position, were coupled with primary acceptors 27-29 in the presence of TMSOTf, the corresponding disaccharides were obtained in excellent yields (88-94\%) with high $\beta$-selectivity $(\alpha / \beta=1 / 26-40$, entries 1-4, Table 1). However, when benzyl sulfonyl was used as an electron-withdrawing group at C-3, the selectivity obtained with donor 26 was reversed and the corresponding disaccharides were obtained with preferential $\alpha$-selectivity $(\alpha / \beta=10-16 / 1$, entries 5 and 6, Table 1).

Very recently, Nifantiev et al. studied the effect of a 3-O-acyl substituent on the stereoselectivity obtained with either conformationally flexible or conformationally restricted glucosyl

Table 1 The effect of a 3-O-acyl protection on the stereoselectivity of mannosylation

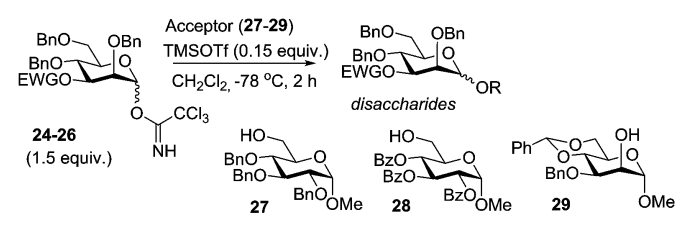

\begin{tabular}{|c|c|c|c|c|}
\hline Entry & Donor (EWG) & Acceptor (1.0 equiv.) & $\begin{array}{l}\text { Disaccharide } \\
\text { yield }\end{array}$ & $\alpha / \beta$ ratio \\
\hline 1 & $24(\mathrm{Ac})$ & 27 & $91 \%$ & $1 / 25.9$ \\
\hline 2 & 24 (Ac) & 28 & $94 \%$ & $1 / 39.0$ \\
\hline 3 & $24(\mathrm{Ac})$ & 29 & $92 \%$ & $1 / 40.4$ \\
\hline 4 & $25(\mathrm{Bz})$ & 28 & $88 \%$ & $1 / 29.6$ \\
\hline 5 & $26\left(\mathrm{SO}_{2} \mathrm{Bn}\right)$ & 27 & $95 \%$ & $15.9 / 1$ \\
\hline 6 & $26\left(\mathrm{SO}_{2} \mathrm{Bn}\right)$ & 28 & $93 \%$ & $10.2 / 1$ \\
\hline
\end{tabular}


Table 2 The effect of a 3-O- and 6-O-acyl protection on the stereoselectivity of glucosylation ${ }^{a}$

$$
\mathrm{R}_{2} \mathrm{O} \underset{\mathrm{BnO}}{\mathrm{R}_{1} \mathrm{O}} \underset{\mathrm{O}}{\mathrm{O}} \mathrm{O}
$$

30: $R_{1}=R_{2}=O A C ; L G=P T F A I$

$30: R_{1}=R_{2}=O A C ; L G=P T F A I$
$31: R_{1}=O B Z ; R_{2}=O A C ; L G=$ PTFAI

32: $R_{1}=R_{2}=O A C ; L G=S O E t$

$\mathrm{Ph} \underset{\mathrm{R}_{3} \mathrm{O}}{\mathrm{O}}{\underset{\mathrm{BnO}}{\mathrm{O} O} \mathrm{O}}_{\mathrm{O}}^{\mathrm{O}} \mathrm{LG}$

33: $R_{3}=O A C ; L G=P T F A I$

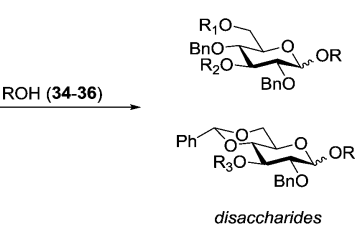

\begin{tabular}{|c|c|c|c|}
\hline Entry & Donor & Acceptor & Yield, $\alpha / \beta$ ratio \\
\hline $1^{\mathrm{a}}$ & 30 & $\underbrace{\mathrm{Ph} T \mathrm{O}}_{34} \underbrace{\mathrm{O}}_{\mathrm{BnO}}$ & $89 \%, 5.3 / 1$ \\
\hline $2^{\mathrm{a}}$ & 30 & ${ }_{35}^{\mathrm{BO}}{ }_{\mathrm{BZO}}^{\mathrm{HO}} \underbrace{}_{\mathrm{BnP}}$ & $93 \%, 11.2 / 1$ \\
\hline $3^{\mathrm{a}}$ & 31 & ${ }_{36}^{\mathrm{BzO}} \underbrace{}_{\mathrm{BnO}}$ & $93 \%, 16.4 / 1$ \\
\hline $4^{\mathrm{b}}$ & 32 & 34 & $59 \%, 6.8 / 1$ \\
\hline $5^{c}$ & 33 & 35 & $96 \%, 5.9 / 1$ \\
\hline
\end{tabular}

donors. ${ }^{49}$ As depicted in Table 2, when $N$-phenyltrifluoroacetimidate (PTFAI) donor $\mathbf{3 0}$ bearing acetyl groups at C-3 and C-6 was reacted with glycosyl acceptors $\mathbf{3 4}$ and 35 the corresponding disaccharides were obtained in good yields and with high selectivities $(\alpha / \beta=5.3-11.2 / 1$, entries 1 and 2$)$. When glycosyl donor 31, wherein the C-6 acetyl was replaced with C-6 benzoyl, was used, a further increase in selectivity was observed $(\alpha / \beta=16.4 / 1$, entry 3). In this context, 3,6-di-O-acetyl protected sulfoxide donor 32 provided lower yield and stereoselectivity (entry 4). A similar selectivity, albeit excellent yield, was observed with conformationally restricted 4,6-O-benzylideneprotected glucosyl donor 33 (96\% yield, $\alpha / \beta=5.9 / 1$, entry 5 ). The effect of steric bulkiness or strong electron-withdrawing properties of remote substituents, particularly those at C-6, have been known for a while. The beneficial effect of such substituents on 1,2-cis glucosylation and galactosylation was attributed to shielding (steric or electronic) of the top face of the ring, therefore favoring nucleophilic attack from the opposite side. ${ }^{15 b, 50}$

A recent study with 2-azido-2-deoxy sugars revealed an interesting relationship between the stereoselectivity and the effect of remote participating groups in $\mathrm{GalN}_{3}$ and $\mathrm{GlcN}_{3}$ sugars. ${ }^{51}$ Over the course of this study it was observed that for $\mathrm{GlcN}_{3}$ sugars, acetyl groups at C-3 and C-6 positions show more $\alpha$-directing effects whereas 4 - $O$-acetyl is more $\beta$-directing. ${ }^{52}$ Crich showed that bulky 3-O-tert-butyldimethylsilyl (TBDMS) can push the axial 2-O-benzyl of mannosyl donors towards the anomeric center, thereby hindering nucleophilic attack from the top face, leading to poor $\beta$-selectivity. ${ }^{53}$ On the other hand, naphthylpropargyl ether protection at C-2 or C-3 favors high $\beta$-manno selectivity. ${ }^{54}$ Hung and co-workers developed a series of orthogonally protected D-glucoaminyl donors for stereoselective introduction of $\alpha$-linkages into heparin-related sequences. ${ }^{55}$ The most advantageous protecting group pattern was determined to be a 2-azido functionality, 2-naphthylmethyl (2-NAP) group at C-4, and $p$-bromobenzyl ( $p$-BrBn) at C-3, and TBDPS at C- 6 positions. The $\alpha$-directing effect of $4-O-p-B r B n$ and 6-O-TBDPS groups was deemed to be steric, preventing the attack of a glycosyl acceptor from the unwanted top face.

Codee and co-workers investigated the use of a 2-azidomannouronate ester donor for glycosidation, and observed high 1,2-cis selectivity. ${ }^{56}$ On gaining an insight into the reaction mechanism, it was concluded that when thiophenyl donor $\mathbf{3 7}$ is activated in the presence of diphenyl sulfoxide and triflic anhydride, anomeric triflate $\mathbf{3 8}$ is formed (Scheme 5). The latter exists as an interchangeable mixture of conformers with the ${ }^{1} \mathrm{C}_{4}$ chair as the predominant species. In principle, triflate $\mathbf{3 8}$ can lead to the $\beta$-linked product via an $\mathrm{S}_{\mathrm{N}}$ 2-like displacement. Alternatively, the reaction can proceed via an $\mathrm{S}_{\mathrm{N}} 1$-like pathway. In this case, the oxacarbenium ion intermediate will preferentially adopt the ${ }^{3} \mathrm{H}_{4}$ half-chair conformation, which closely resembles the major ${ }^{1} \mathrm{C}_{4}$ conformation of triflate 38. In this case, the C-5 carboxylate occupies a pseudo-axial position allowing for stabilization of the positive charge. The incoming nucleophile 39 will then attack from the $\beta$-face to produce disaccharide $\mathbf{4 0}$ with complete 1,2-cis selectivity in $85 \%$ yield.

A very different stereodirecting effect was discovered for remote picolinyl (Pic) and picoloyl (Pico) substituents. As aforementioned, a picolinyl at C-2 formally participates at the anomeric center and gives 1,2-trans glycosides via the six-membered ring intermediate. ${ }^{35 b}$ The action of the remote picolinyl and related picoloyl substituents is totally different. Not being able to participate at the anomeric center directly, picolinyl nitrogen forms a hydrogen bond with the incoming glycosyl acceptor. As a result, a very high facial selectivity, always syn in respect to the picolinyl substituent, is observed. ${ }^{57}$ This rather unexpected involvement of remote picolinyl substituents was termed as H-bond-mediated aglycone delivery (HAD). Based on the above hypothesis, it was shown that under high dilution conditions (5 mM), 4-O-picoloyl or picolinyl glucosyl donors (41-45) provide faster reaction times and enhanced selectivity compared to those obtained in standard concentration $(50 \mathrm{mM})$. Thus, glucosyl donors $\mathbf{4 1}$ and $\mathbf{4 2}$ provided high levels of $\alpha$-selectivity, particularly with $O$-picoloyl protection $(\alpha / \beta=$ $>25 / 1$, entry 1 , Table 3). Galactosyl donor 43 and rhamnosyl

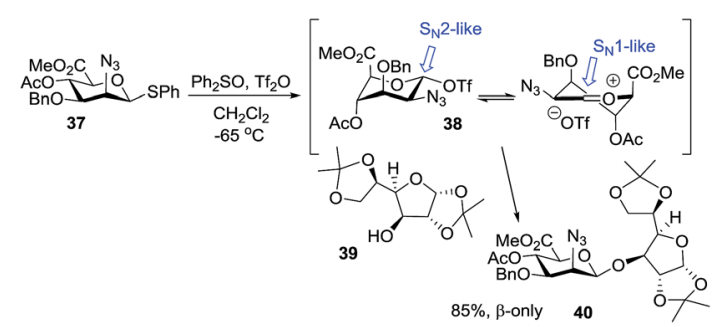

Scheme 5 Rationalization of the high $\beta$-selectivity achieved with 2azidomannouronate donor 37 . 
Table $3 \quad \mathrm{H}$-bond-mediated aglycone delivery (HAD)

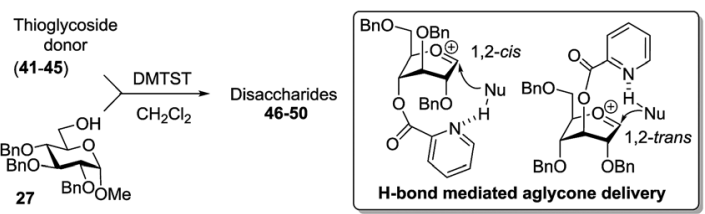

\begin{tabular}{|c|c|c|c|c|c|}
\hline Entry & Donor & Conc. 27 & Time & Product (yield) & $\alpha / \beta$ ratio \\
\hline 1 & 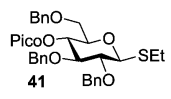 & $5 \mathrm{mM}$ & $4 \mathrm{~h}$ & 46 (73\%) & $>25 / 1$ \\
\hline 2 & ${ }_{42}^{\mathrm{BnO}} \underbrace{\mathrm{BnO}}_{\mathrm{BnO}}$ & $5 \mathrm{mM}$ & $5 \mathrm{~h}$ & $47(86 \%)$ & $5.3 / 1$ \\
\hline 3 & BnO & $5 \mathrm{mM}$ & $1 \mathrm{~h}$ & $48(95 \%)$ & $>1 / 25$ \\
\hline 4 & $\underset{\substack{\mathrm{PicoO} \\
\mathbf{B n}}}{\mathrm{OBn}}$ & $50 \mathrm{mM}$ & $15 \mathrm{~min}$ & $49(94 \%)$ & $>1 / 25$ \\
\hline 5 & $\underbrace{\mathrm{BzZO}}_{\text {SPh }}$ & $5 \mathrm{mM}$ & $2.5 \mathrm{~h}$ & $50(91 \%)$ & $1 / 18.5$ \\
\hline
\end{tabular}

donor 44 gave high $\beta$-selectivity $(\alpha / \beta=>1 / 25$, entries 3 and 4 , respectively). As an extension to this study, Demchenko and co-workers showed that the presence of a 3-O-picoloyl group in mannosyl donor 45 can effectively provide $\beta$-mannosides with high stereoselectivity at room temperature $(\alpha / \beta=1 / 18.5$, entry 5$).{ }^{58}$

The applicability of this approach was demonstrated for the synthesis of oligosaccharide 53 containing both primary and secondary $\beta$-mannosidic linkages (Scheme 6a). Thus, when 3-O-picolylated mannosyl donor $\mathbf{4 5}$ was reacted with glycosyl acceptor $\mathbf{2 7}$ in the presence of DMTST, $\beta$-linked disaccharide $\mathbf{5 0}$ was obtained with $\alpha / \beta=1 / 18.5$ selectivity. The 3-O-picoloyl group of $\mathbf{5 0}$ was then selectively removed using copper(II)

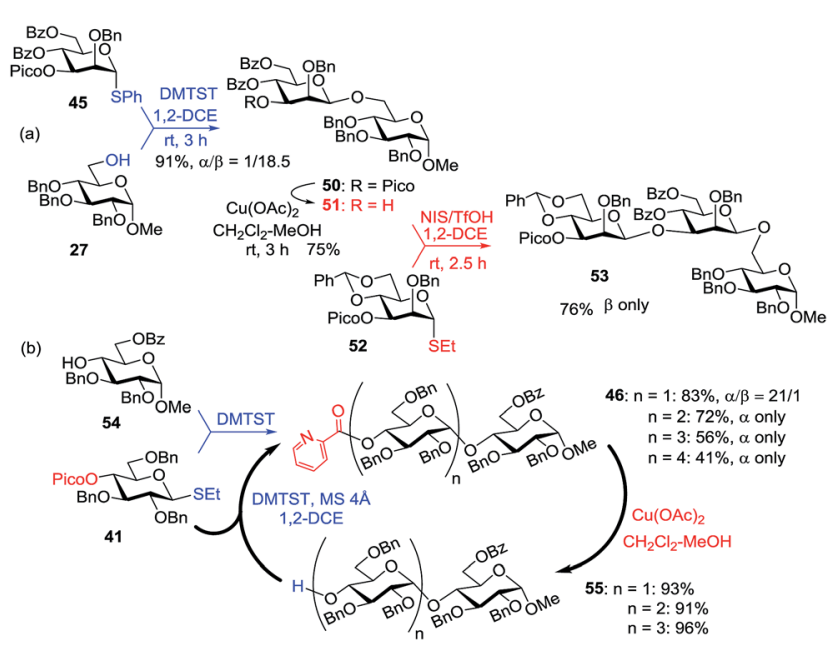

Scheme 6 HAD synthesis of $\beta$-mannan and $\alpha$-glucan. acetate and the resulting acceptor $\mathbf{5 1}$ was coupled with mannosyl donor 52, to provide the desired trisaccharide $\mathbf{5 3}$ in $\mathbf{7 6 \%}$ yield and with complete $\beta$-selectivity.

Further application of the HAD method has resulted in the synthesis of linear and branched $\alpha$-glucans. ${ }^{59}$ As depicted in Scheme 6b, when 4-O-picoloyl glucosyl donor $\mathbf{4 1}$ was glycosylated with acceptor $\mathbf{5 4}$ in the presence of DMTST, disaccharide 46 was obtained in $83 \%$ yield $(\alpha / \beta=21 / 1)$. The 4 -O-picoloyl group was then selectively removed with copper(II) acetate to form the second generation glycosyl acceptor 55. The process was repeated to obtain pentasaccharide $46(n=4)$ with $41 \%$ yield and complete $\alpha$-selectivity.

At first, the HAD approach was limited to $S$-ethyl glycosyl donors and only in the presence of DMTST, in high dilution, and low temperature. Other leaving groups gave much lower stereoselectivity. ${ }^{60}$ Combining the mechanistic studies of the HAD reaction and bromine-promoted glycosylations (vide infra) Yasomanee and Demchenko devised a very effective method that allows for highly stereoselective $\alpha$-glucosidation of practically all common leaving groups ( $S$-phenyl, $S$-tolyl, $S / O$-imidates) at regular concentrations and ambient temperature. ${ }^{60}$ Young and co-workers extended the HAD approach to $\beta$-stereoselective $\mathrm{D}$ - and $\mathrm{L}$-arabinofuranosylation. ${ }^{61}$ In this case, $5-\mathrm{O}-(2-$ quinolinecarbonyl) substituted arabinose was employed as the glycosyl donor. Mong and co-workers successfully applied 6-O-picoloylated glycosyl donors to the synthesis of $\beta$-2-deoxy glycosides. $^{25 g}$

\section{C.3. Conformation-restraining cyclic protecting groups}

Torsional effects induced by cyclic protecting groups may also strongly affect the stereoselectivity of glycosylation. The bestknown example of this effect is the work by Crich and co-workers on the synthesis of $\beta$-mannosides. ${ }^{62}$ Thus, it has been demonstrated that 4,6-O-benzylidene-protected thioglycoside donors give superior $\beta$-manno selectivity in comparison to that achieved with donors lacking this type of protection. ${ }^{63}$ The stereoselectivity observed was rationalized by carrying out experiments in which the benzylidene protected sulfoxide donor ${ }^{64}$ is pre-activated using $\mathrm{Tf}_{2} \mathrm{O}$ to form a sulfonium salt, which collapses into the $\alpha$-triflate that exists in dynamic equilibrium with the contact ion pair. The presence of glycosyl triflate intermediates in mannosylation was also recognized with thioglycoside,${ }^{65}$ TCAI ${ }^{66}{ }^{2}$-(hydroxycarbonyl)benzyl, ${ }^{67}$ hemiacetal ${ }^{68}$ pentenoate, ${ }^{69}$ and phthalate ${ }^{70}$ donors, all protected as 4,6-benzylidene acetals. It is believed that the closely associated triflate counterion shields the $\alpha$-face and $\beta$-linked product forms preferentially. An $\alpha$-deuterium kinetic isotope effect (KIE) study indicated substantial oxacarbenium ion character of this reaction pathway, ruling out the possibility of a bimolecular displacement. ${ }^{62 b}$ Similar conclusions were made as a result of KIE experiments with mannosyl iodides. ${ }^{71}$ The deactivating effect of benzylidene substituents was found to be a combination of torsional strain, ${ }^{72}$ restricting the conformational flexibility of the ring, and enhanced electron-withdrawal. ${ }^{73}$ The latter effect is due to locking the hydroxymethyl group in the conformation wherein the C6-O6 
bond is directed away from $O-5$. This may cause additional destabilization of the oxacarbenium intermediate that seeks for compensation from tight coordination to the counter anion.

While the study of 4,6-O-benzylidene protected glycopyranosyl triflates revealed high $\beta$-selectivities with mannosyl donors, high $\alpha$-selectivity is obtained with glucosyl donors (Table 4). ${ }^{62 a}$ This finding was rationalized by the fact that the $\alpha$-triflate intermediate undergoes equilibrium with its more reactive $\beta$-counterpart rather than with the oxacarbenium ion intermediate. The rate and equilibrium constant for the formation of $\beta$-glucosyl triflate are such that it preferentially forms the $\alpha$-linked product.

Many useful applications have evolved from the Crich methodology for $\beta$-mannosylation. For instance, the direct syntheses of $\beta$ - $(1 \rightarrow 2)$ - and $\beta$ - $(1 \rightarrow 4)$-mannans represent the power of this technique. ${ }^{74}$ As depicted in Scheme 7 , synthesis of the $(1 \rightarrow 2)$-mannan was achieved by means of the sulfoxide coupling protocol. Thus, 2-O-paramethoxybenzyl protected sulfoxide donor 63 was reacted with cyclohexanol 64 in the presence of triflic anhydride and 2,4,6-tri-tert-butylpyrimidine (TTBP) to afford $\beta$-mannoside $65(n=1)$ in $77 \%$ yield. The latter was deprotected with DDQ to give glycosyl acceptor 66 . Repetition of glycosylation-deprotection steps led to a series of $(1 \rightarrow 2)$-linked homologs. For instance, octasaccharide 65 $(n=8)$ was obtained in $64 \%$ yield $(\beta / \alpha=4.5 / 1)$. In this context, the $(1 \rightarrow 4)$-linked mannan was prepared from thioglycoside donors activated using sulfinamide methodology.

To study the influence of similar conformationally rigid protecting groups, on the selectivity obtained, Werz and coworkers synthesized a variety of mannosyl donors with a spiroannulated cyclopropane ring at C-5 bearing one hydroxyl group. ${ }^{75}$ It was shown that the cyclopropane group leads to fixation of the chair-like conformation, similar to that shown for 4,6-benzylidene protected sugars although high $\beta$-selectivity was not achieved.

Table 4 Stereodirecting effect of 4,6-O-benzylidene acetal

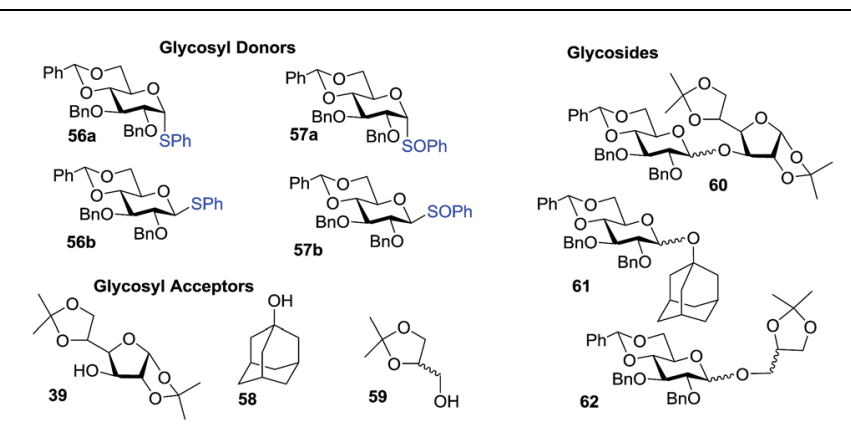

\begin{tabular}{lllll} 
Entry & Donor, acceptor & Coupling reagent & Product & Yield, $\alpha / \beta$ ratio \\
\hline 1 & $\mathbf{5 6 a}, \mathbf{3 9}$ & PhSOTf & $\mathbf{6 0}$ & $70 \%,>95 / 5$ \\
2 & $\mathbf{5 6 b}, \mathbf{3 9}$ & PhSOTf & $\mathbf{6 0}$ & $80 \%,>95 / 5$ \\
3 & $\mathbf{5 7 b}, \mathbf{5 8}$ & $\mathrm{Tf}_{2} \mathrm{O}$ & $\mathbf{6 1}$ & $63 \%,>95 / 5$ \\
4 & $\mathbf{5 7 a}, \mathbf{5 9}$ & $\mathrm{Tf}_{2} \mathrm{O}$ & $\mathbf{6 2}$ & $89 \%,>95 / 5$
\end{tabular}

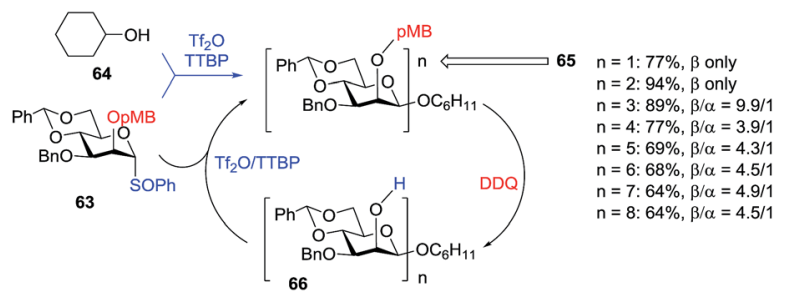

Scheme $7 \quad \beta$-Linked mannans by the sulfoxide protocol.

Kerns discovered that 2,3-trans-oxazolidinone-protected glucosaminyl donors provide excellent 1,2-cis selectivity in glycosylations (Scheme 8a). ${ }^{76}$ Although high $\alpha$-selectivity could be obtained, the oxazolidinone protected donor showed propensity to undergo side reactions, such as $\mathrm{N}$-glycosylation or $\mathrm{N}$-sulfenylation. To rectify this, Kerns et al. ${ }^{77}$ and Oscarson et al. ${ }^{78}$ reported the use of $N$-acetylated oxazolidinones. ${ }^{76 a, 77 a}$ These donors showed switchable stereoselectivity in glycosylation that was achieved by tuning the reaction conditions. ${ }^{79}$ This interesting finding stimulated further studies. Mechanistically it was suggested that the $\beta$-linked product is formed initially, which rapidly anomerizes into the corresponding $\alpha$-anomer. The presence of the oxazolidinone ring is the key for this anomerization to occur, which was found to proceed via endocyclic C1-O5 bond cleavage.$^{80}$ For instance, when $\mathrm{N}$-acetyl-2,3-oxazolidinone protected donor 67 was reacted with glycosyl acceptor 68 in the presence of NIS and AgOTf, disaccharide 69 was obtained in $82 \%$ yield ( $\alpha$-only, Scheme $8 \mathrm{~b}$ ). Manabe, Ito and their co-workers reported $\mathrm{N}$-benzylated 2,3-oxazolidinone donors for 1,2-cis glycosylation. ${ }^{81}$ Thus, when glycosyl donor 70 was glycosidated with acceptor $\mathbf{7 1}$ in the presence of $N$-(phenylthio)$\varepsilon$-caprolactam and triflic anhydride, disaccharide 72 was obtained in $52 \%$ yield with complete $\alpha$-selectivity (Scheme $8 \mathrm{c}$ ).

Crich et al. showed that the 2,3-O-carbonate protecting group is highly $\alpha$-selective for mannosylation and rhamnosylation. ${ }^{\mathbf{5 3 , 8 2}}$ In contrast, 3,4-O-carbonate protected rhamnosyl donors showed moderate $\beta$-selectivities owing to the electron withdrawing but non-participating nature of this group. Crich also reported the synthesis of $\beta$-glucosides using 2,3-O-carbonate protected glucosyl donors. ${ }^{83}$ It was suggested that the conformation restricting trans-fused ring favors the formation of an

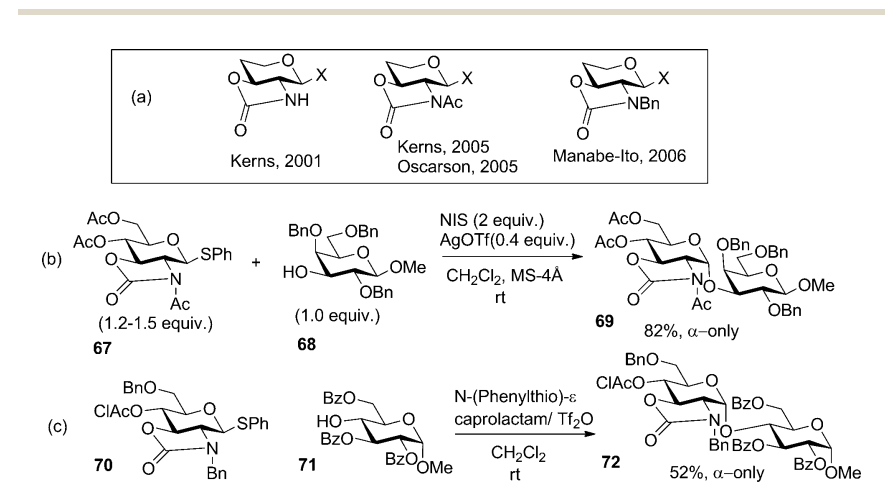

Scheme 8 Selective $\alpha$-glycosylation with $N$-acetyl- and $N$-benzyl2,3-oxazolidinone-protected donors 67 and 70 . 
$\alpha$-triflate intermediate over the formation of an oxacarbenium ion. The effect of 3,4-O-carbonate protection was found to be weaker with a slight preference toward $\beta$-selectivity. ${ }^{25 d}$ Ye and co-workers studied 2,3-O-carbonyl protected glucose and galactose donors for pre-activation-based glycosylation. ${ }^{84}$ These reactions were generally $\beta$-stereoselective, but Lewis acid additives were found to favor $\alpha$-stereoselectivity (vide infra). A beneficial effect of a bulky 4,6-O-di-tert-butylsilylene (DTBS) protecting group ${ }^{85}$ on $\alpha$-selective galactosylation and galactosamination was recently applied to the synthesis of a series of human $\mathrm{ABO}$ histo-blood group type 2 antigens by Kiso and co-workers. ${ }^{86}$

\section{Effect of the glycosyl acceptor}

Many examples wherein different glycosyl acceptors have different selectivities can be seen throughout the text of this review. A rule of thumb is that the alcohol reactivity is inversely correlated with the stereoselectivity and the most reactive hydroxyls give the lowest $\alpha / \beta$-ratios: the stronger the nucleophile, the faster the reaction, and therefore the more difficult it is to control its outcome. As an example, glycosylation of the axial 4-OH of galactose often gives excellent 1,2-cis stereoselectivity. Occasionally, primary hydroxyls provide higher stereoselectivity in comparison to that of secondary hydroxyl groups. This can serve as evidence for the glycosylation reaction proceeding via a bimolecular mechanism, at least partially. Primary alcohols also gave higher stereoselectivity in H-bondmediated aglycone delivery reactions mediated by remote picolinyl groups. ${ }^{57}$

It is well-established that ester electron-withdrawing substituents reduce the electron density of the neighboring hydroxyl group, lowering its nucleophilicity. ${ }^{87}$ This may improve stereoselectivity, as the reaction can be carried out in a more controlled manner. Recently, Demchenko and co-workers have shown that electron-withdrawing acyl protecting groups have a dramatic effect on the stereoselectivity obtained with thiocyanates as glycosyl donors. ${ }^{88}$ Thus, when thiocyanate 73 was reacted with acyl-protected acceptors $\mathbf{7 4}$ and $\mathbf{7 5}$, the corresponding disaccharides $\mathbf{7 7}$ and $\mathbf{7 8}$ were obtained with complete $\alpha$-selectivity $(\alpha / \beta=>25 / 1$, Scheme 9$)$. However, when benzylprotected acceptor $\mathbf{7 6}$ was used instead, the stereoselectivity dropped $(79, \alpha / \beta=8.3 / 1)$.

Very recently, Toshima and co-workers reported a novel approach that makes use of the chiral recognition of aglycones. ${ }^{89}$ Thus, in glycosylations of racemic alcohols in the presence of a chiral Brønsted acid activator, one enantiomer was glycosylated preferentially and the glycosides were obtained with high stereoselectivity and yields.

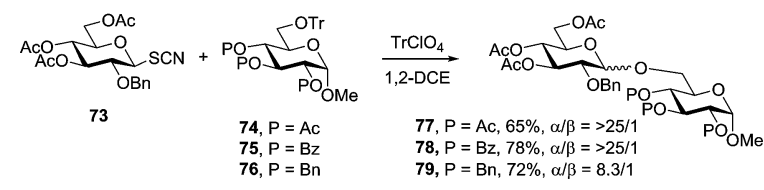

Scheme 9 Acyl groups in acceptors enhance stereoselectivity.

\section{E. Effect of the reaction conditions}

\section{E.1. Temperature}

Kinetically controlled glycosylations at lower temperatures generally favor $\beta$-glycoside formation, ${ }^{90}$ although converse observations have also been reported. ${ }^{91}$ Since the $\alpha$-glycoside is thermodynamically favored due to the anomeric effect, it is predominantly formed at high temperatures. A number of examples have been presented throughout other parts of this review.

\section{E.2. Solvent}

The effect of reaction solvent on the selectivity of the glycosylation reaction has been widely studied. In general, polar reaction solvents increase the rate of $\beta$-glycoside formation via charge separation between $O-5$ and $\beta-O-1$. If the synthesis of $\alpha$ glycosides is desired, $\mathrm{CH}_{2} \mathrm{Cl}_{2}, \mathrm{ClCH}_{2} \mathrm{CH}_{2} \mathrm{Cl}$ or toluene would be suitable candidates as the reaction solvent. However, there are more powerful forces than simple solvation that have to be taken into consideration. It has been shown that ethereal solvents have a tendency to drive glycosylation in an $\alpha$-selective fashion, while nitrile solvents increase the amount of $\beta$-glycoside formation. ${ }^{42 b, 92}$ These observations were rationalized as follows: ether type reaction solvents such as diethyl ether, ${ }^{93}$ tetrahydrofuran, ${ }^{93}$ or dioxane ${ }^{94}$ lead to the preferential formation of the equatorial intermediate. On the other hand, if the reactions are performed in acetonitrile, the nitrilium cation formed in situ exclusively adopts an axial orientation, allowing stereoselective formation of equatorially substituted glycosides (Scheme 10). This approach permits the formation of 1,2-trans glucosides with good stereoselectivity even with glycosyl donors bearing a non-participating substituent.

Recently, the Mong group proposed a revised mechanism for glycosylation in nitrile solvents. ${ }^{95}$ Accordingly, the oxacarbenium ion intermediate interacts with the nitrile solvent producing mixtures of $\alpha$ - and $\beta$-glycosyl nitrilium intermediates. Though the formation of 1,2-cis nitrilium species is favored by the anomeric effect, it is further reinforced through the participation of $0-2$ (Scheme 10). The resulting glycosyl oxazolinium intermediate is then attacked by a nucleophile from the top face leading to formation of the $\beta$-product.

Many applications of solvent systems controlling reaction stereoselectivity are known. A representative example shown in Table 5 makes use of an $\mathrm{N}$-trichloroacetyl carbamate leaving group introduced by Redlich ${ }^{96}$ and Vankar. ${ }^{97}$ Omura et al. showed that the stereoselectivity of glycosylation can be

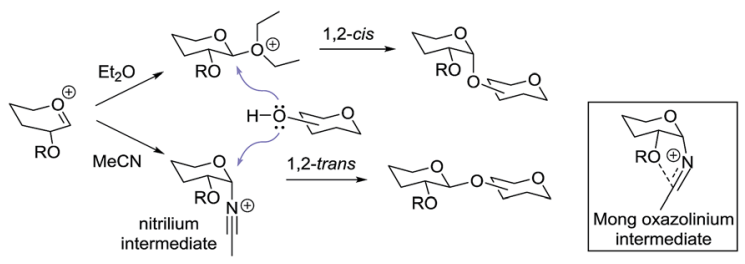

Scheme 10 Effect of the reaction solvent. 
Table 5 One-pot synthesis and glycosidation of carbamates

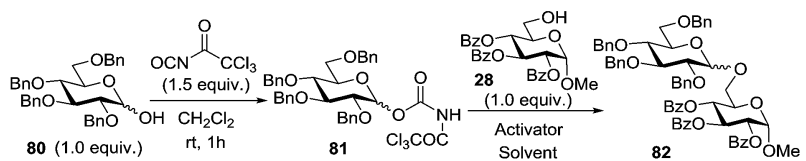

\begin{tabular}{lllll}
\hline Entry & Activator & Solvent & Reaction conditions & Yield, $\alpha / \beta$ ratio \\
\hline 1 & TMSClO $_{4}(1.5$ equiv. $)$ & $\mathrm{Et}_{2} \mathrm{O}$ & $0{ }^{\circ} \mathrm{C}, 0.5 \mathrm{~h}$ & $99 \%, 93 / 7$ \\
2 & TMSOTf $(1.5$ equiv. $)$ & $\mathrm{EtCN}$ & $-40{ }^{\circ} \mathrm{C}, 0.5 \mathrm{~h}$ then $-23{ }^{\circ} \mathrm{C}, 0.5 \mathrm{~h}$ & $88 \%, 8 / 92$ \\
\hline
\end{tabular}

reversed by simply switching the solvent. ${ }^{98}$ Thus, when $\mathrm{N}$-trichloroacetyl carbamate $\mathbf{8 1}$ was glycosidated with acceptor 28 in the presence of $\mathrm{TMSClO}_{4}$ in diethyl ether as the solvent, disaccharide 82 was formed with high $\alpha$-selectivity (entry 1). Conversely, high $\beta$-selectivity could be achieved by activation with TMSOTf in EtCN (entry 2). Apparently, this example makes use of the promoter and temperature effects.

Huang et al. have recently studied the solvent and additive effects on the stereochemical outcome of the thioglycosidebased glycosylation strategy. ${ }^{99}$ When donor 83 was pre-activated with $p$-TolSOTf, formed in situ from $p$-Tolscl and AgOTf (3 equiv.) in diethyl ether disaccharide 87 was obtained in $67 \%$ yield $(\alpha / \beta=1.1 / 1$, Scheme 11). When the amount of AgOTf was decreased to 1.1 equiv., significant change in $\alpha$-selectivity was observed $(\alpha / \beta=6 / 1)$. In addition, when the reaction was performed by increasing the volume of diethyl ether 10 fold, further enhancement in $\alpha$-selectivity was observed $(\alpha / \beta=10 / 1)$. On the other hand, when dichloromethane was used as the reaction solvent, the stereoselectivity was switched $(\alpha / \beta=1 / 8)$. With the belief that glycosyl triflates are formed as the key reaction intermediates, the observed stereoselectivity was rationalized as follows. The reactions performed in diethyl ether proceed through a double-inversion mechanism. Under dilute conditions and with lower excess of AgOTf, solvent participation becomes more effective, resulting in higher $\alpha$-selectivity. In the case of dichloromethane, due to the non-nucleophilic nature of the solvent, the reaction is likely to proceed via an $\mathrm{S}_{\mathrm{N}} 2$-like triflate displacement pathway leading to $\beta$-glycosides (Scheme 11).

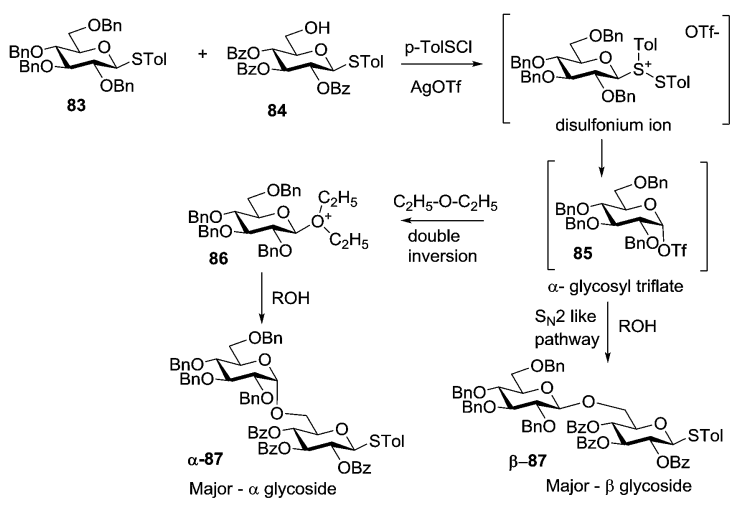

Scheme 11 The solvent effect on preactivation-based glycosylation.
Ito and co-workers developed a high-throughput screening system to study the synergistic solvent effect of combined ethereal and halogenated solvents on the course of glycosylation. ${ }^{92}$ This study employed the use of glycosyl donors, which were isotopically labeled with per-deuterated protecting groups: benzyl ether (Bn- $\left.d_{7}\right)$ and $d_{10}$-cyclohexylidene ketal. The labeled donor was glycosidated in the presence of MeOTf as the activator and 2,6-di-tert-butyl-4-methylpyridine (DTBMP) in various solvents.

As depicted in Scheme 12, when per-deuterated benzyl ether protected thioglycoside donor $\mathbf{8 8}$ was reacted with per-deuterated glycosyl acceptor $\mathbf{8 9}$ in the presence of methyl triflate (MeOTf) as a promoter, disaccharide $\mathbf{9 0}$ was obtained with selectivity up to $\alpha / \beta=19.5 / 1$. A mixture of $\mathrm{CHCl}_{3} / \mathrm{Et}_{2} \mathrm{O}$ or $\mathrm{CHCl}_{3} /$ cyclopentyl methyl ether (CPME) $1 / 1(\mathrm{v} / \mathrm{v})$ provided the best results and the use of such solvent systems was extended to the synthesis of a variety of 1,2-cis linkages. ${ }^{92,100}$ The beneficial effect of high temperature on $\alpha$-selectivity has also been noted. The advantage of using Bn- $d_{7}$ is the "disappearance" of all benzylic methylene signals at around 4-5 ppm, thereby making it easier to interpret the proton NMR spectra of the products.

Mong and co-workers took a different direction in studying the reaction solvent effect by using dimethylformamide (DMF) as a co-solvent, a rather uncommon reaction solvent in glycosylations. ${ }^{101}$ This study employed two conceptually different protocols for glycosylation. First, a conventional method (procedure A, Table 6), wherein a mixture of glycosyl donor, acceptor, and DMF was activated with NIS and TMSOTf. As shown in Table 6, reaction of benzylated donor 91 with acceptor 92 gave moderate stereoselectivity $(82 \%, \alpha / \beta=6 / 1$, entry 1$)$ in the presence of 1.5 equiv. of DMF. The increase in the amount of DMF to 3 and 6 equiv. (entries 2 and 3, respectively)

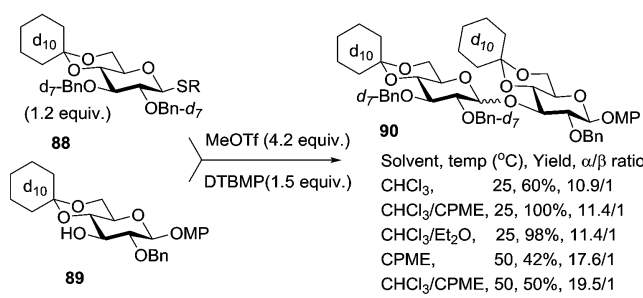

Scheme 12 Solvent and temperature effects. 
Table 6 Investigation of DMF-mediated glycosylations

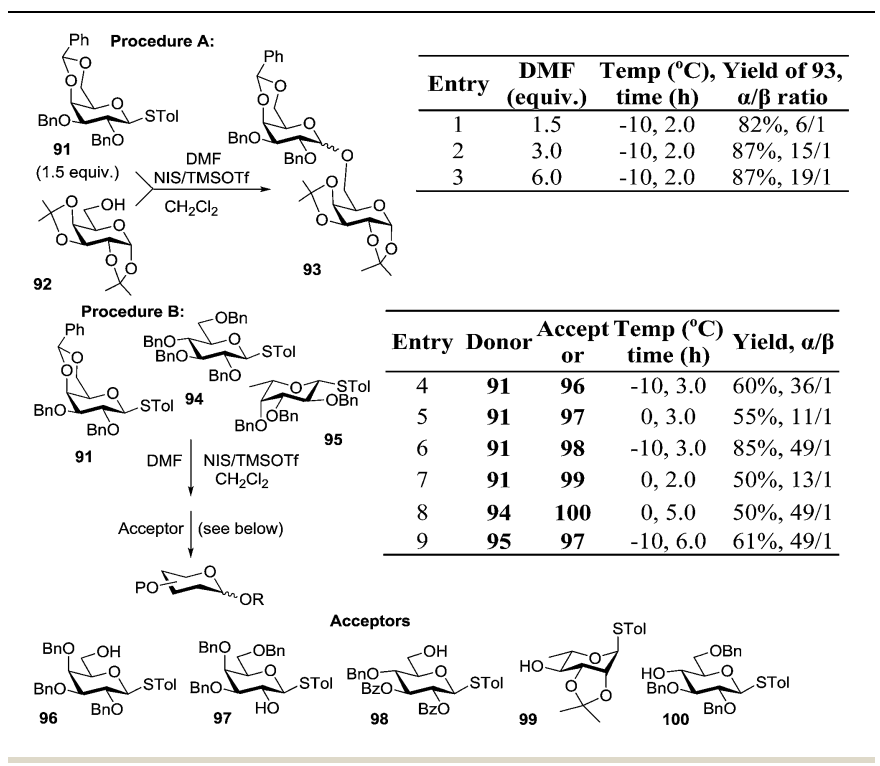

translated into a significant increase in $\alpha$-stereoselectivity (up to $\alpha / \beta=19 / 1$, entry 3 ).

The results obtained using procedure $\mathbf{A}$ were then applied to the investigation of the effectiveness of the pre-activation based glycosylation procedure B. Accordingly, the glycosyl donor was reacted with NIS and TMSOTf in the presence of DMF followed by the addition of the glycosyl acceptor. All glycosylations between thioglycoside donors 91, 94, or 95 and acceptors 96-100 proceeded with very high $\alpha$-selectivity $(\alpha / \beta=11-49 / 1$, entries 4-9, Table 6).

This modulating effect of DMF, which was particularly evident in the preactivation-based protocol (procedure B) was rationalized as follows. DMF involvement traps the glycosyl oxacarbenium ion resulting in an equilibrating mixture of $\alpha / \beta$-glycosyl $O$-imidates (Scheme 13 ). The more reactive $\beta$-imidate will react faster with the glycosyl acceptor producing the desired $\alpha$-glycoside with high selectivity. This procedure implies an $\mathrm{S}_{\mathrm{N}} 2$-like inversion en route to the products of glycosylation. Interestingly, the use of ethereal solvents had no effect on the further improvement of stereoselectivity, irrespective of the type of ethereal solvent used.

Encouraged by the $\alpha$-stereodirecting effect of DMF, the preactivation protocol was then extended to a sequential one-pot oligosaccharide synthesis. ${ }^{101}$ As depicted in Scheme 14, trisaccharide 105 containing two contiguous 1,2-cis linkages was efficiently assembled in an overall yield of $52 \%$ from building blocks 101, 102 and 104. An interesting feature of DMF as an

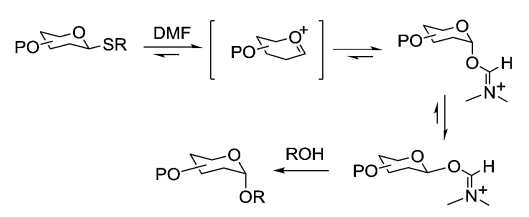

Scheme 13 DMF-mediated glycosylation.

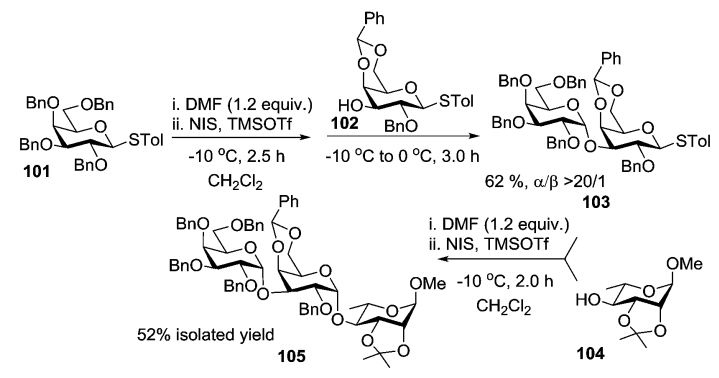

Scheme 14 DMF-mediated synthesis of trisaccharide 105.

additive to the one-pot multi-step synthesis is that it is regenerated after the first coupling and hence can be engaged in the subsequent modulation cycles.

\section{E.3. Promoter, additives, and chelators}

Many decades ago, glycosylation of poorly nucleophilic acceptors was sluggish and inefficient. ${ }^{102}$ Early attempts to improve the glycosylation process by Zemplen ${ }^{103}$ and Helferich ${ }^{104}$ also revealed the necessity to find a delicate balance between the reactivity and stereoselectivity because it was noted that faster reactions often result in decreased stereoselectivity and vice versa ${ }^{105}$ It has become general knowledge that milder activating conditions are beneficial for 1,2-cis glycosylation. Thus, halide ion-catalyzed reactions gave the best results for glycosylation with glycosyl bromides ${ }^{30}$ and iodides. ${ }^{106,107}$

Thioglycosides often give higher selectivity when activated with a mild promoter, such as iodonium dicollidine perchlorate (IDCP) ${ }^{108}$ Recently, Demchenko and co-workers investigated the glycosidation of thioglycosides in the presence of bromine, another mild activator. ${ }^{31}$ It was demonstrated that bromine-mediated glycosylation of thioglycoside 106 leads to exclusive $\alpha$-selectivity in products 109-111 (entries 1a, 2a and 3a, Scheme 15). This reaction was monitored by NMR, showing that $\beta$-bromide is the reactive intermediate which, however, can undergo a rapid anomerization into the $\alpha$-linked counterpart. Once formed, the $\alpha$-bromide is totally unreactive under the established reaction conditions, so the yield of glycosylation can be low with secondary alcohols (entries 2a and 3a). It was also shown that the $\alpha$-bromide can be reactivated in the presence of a mercury(II) additive. This pathway was found to be very beneficial for the glycosylation of secondary alcohols (entries $2 \mathrm{~b}$ and $3 \mathrm{~b}$ ), but can compromise the $\alpha$-selectivity of glycosylation with primary alcohols (entry $1 b)$.

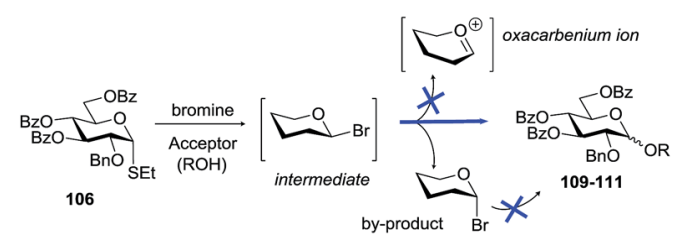

Scheme 15 Stereoselective glycosidation of superdisarmed thioglycoside 106 via reactive $\beta$-bromide intermediate. 
While many of the current methodologies for glycosylation require the use of stoichiometric amounts of promoters, the use of transition metal catalysts helps to achieve greener glycosylation and offers new opportunities for stereocontrol. ${ }^{109}$ Nguyen and co-workers studied palladium(II)-catalyzed glycosidation of TCAI donors using $\mathrm{Pd}\left(\mathrm{CH}_{3} \mathrm{CN}\right)_{4}\left(\mathrm{BF}_{4}\right)_{2}$ or similar catalysts. ${ }^{110}$ This study evolved into the investigation of a series of nickel catalysts providing an efficient means for the glycosidation of $N$ - $p$-methoxybenzylidene-protected 2-amino-2-deoxy TCAI donor. ${ }^{111}$ The nature of the ligand on nickel has been found to be the deciding factor in controlling the stereoselectivity of glycosylation. Thus, it was observed that electron-withdrawing substituents help to decrease the reaction time, which is translated into increased $\alpha$-selectivity. The efficiency of nickelcatalyzed reactions was extended to the synthesis of a number of challenging targets. As summarized in Table 7, $\mathrm{N}$-benzylidene TCAI donor 112 bearing different para substituents was reacted with primary (27-28) and secondary glycosyl acceptors $(58,113-114)$ under catalysis of $\mathrm{Ni}(4-\mathrm{F}-\mathrm{PhCN})_{4}(\mathrm{OTf})_{2}$, to provide disaccharides (115-119) with very high $\alpha$-selectivity.

Recently there has been an explosion in the study of goldcatalyzed activation of alkynes to exploit the low oxophilic character of gold and the excellent functional group compatibilities these catalysts exhibit. ${ }^{112}$ This includes work by Hotha and co-workers where propargyl glycosides were activated using

Table 7 Nickel-catalyzed glycosidation of donor 112

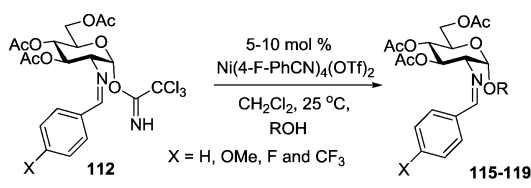

Entry

Scheme 16 Synthesis of 1,2-cis-linked glycosides by activation of thioglycosides in the presence of TBAI.
$\mathrm{Au}(\mathrm{III})$ chloride to give $\alpha / \beta$ mixtures of glycosides and disaccharides in good yields. Yu and co-workers conducted a similar study with glycosyl ortho-alkynylbenzoates under catalytic Au(I) activation conditions. ${ }^{112 d, 112 e}$ Another promising new field is the use of chiral thioureas as organocatalysts for glycosylation. ${ }^{113}$ As of now, this approach is limited to the synthesis of 2-deoxy $\alpha$-glycosides ${ }^{\mathbf{1 1 4}}$ and $\beta$-selective glycosylation with 2-oxygenated sugars. ${ }^{115}$

Bennett and co-workers recently investigated the activation of thioglycosides with $\mathrm{Ph}_{2} \mathrm{SO}$ in the presence of TBAI. It was observed that this reaction proceeds via the intermediacy of glycosyl iodides. ${ }^{116}$ The underpinning idea of using TBAI is that the conversion of $\alpha$-glycosyl triflates into $\beta$-glycosyl iodides would favor the formation of $\alpha$-glycosides. Thus, when $S$-phenyl donor 120 was preactivated using $\mathrm{Ph}_{2} \mathrm{SO} / \mathrm{Tf}_{2} \mathrm{O}$ followed by the addition of TBAI and glycosyl acceptors 2 or 92 , the respective disaccharides 121 (41\%) or 122 (79\%) were obtained in excellent or even complete $\alpha$-stereoselectivity (Scheme 16).

Various additives to promoter systems often influence the stereochemical outcome of glycosylation. Amongst the most remarkable examples is the use of perchlorate ion additive that was found to be very influential in 1,2-cis glycosylation. ${ }^{\mathbf{1 1 7}}$ Very recently, the effectiveness of the use of silver perchlorate as the activator in glycosidation of thioimidates and thioglycosides to provide better 1,2-cis selectivity than that achieved with more common triflates, has been studied. ${ }^{118}$ While studying 2,3-O-carbonyl protected glucose and galactose donors, which are generally $\beta$-stereoselective, Ye and co-workers observed that Lewis acid additives favor $\alpha$-stereoselectivity in preactivationbased glycosylation. ${ }^{84}$ Thus, a catalytic amount of $\mathrm{BF}_{3}-\mathrm{OEt}_{2}$ or $\mathrm{AgBF}_{4}$ as well as 1 equiv. of $\mathrm{AgPF}_{6}$ or $\mathrm{SnCl}_{4}$ completely reversed the stereoselectivity to give $\alpha$-linked products. It was assumed that similar to that proven for 2,3-oxazolidinones, ${ }^{\mathbf{8 0}}$ the initially formed $\beta$-linked product anomerizes into the thermodynamically more stable $\alpha$-anomer, and this anomerization is facilitated by Lewis acid additives.

Demchenko and co-workers observed that multi-dentate metal coordination to the leaving group, along with a protecting group at $O-6$ and/or $O-5$, has a strong effect on the stereoselectivity of chemical glycosylation (Scheme 17). It was demonstrated that platinum(Iv) complexation of 6-O-picolinyl or 6-O-bipyridyl to the leaving group, such as thiazolinyl, has a pronounced effect on the stereoselectivity of glycosylation. ${ }^{119}$ While the glycosidation of thioimidate donor $\mathbf{1 2 3}$ with acceptor

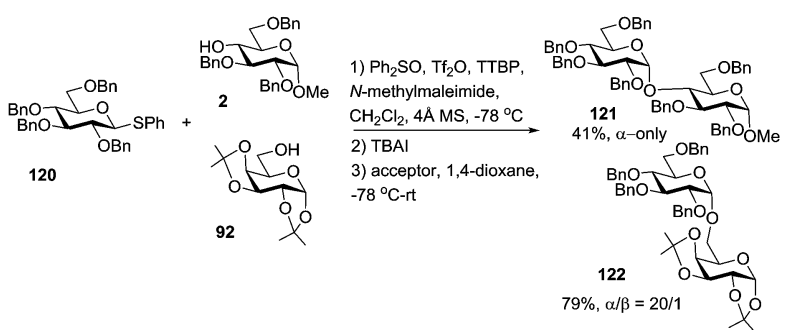




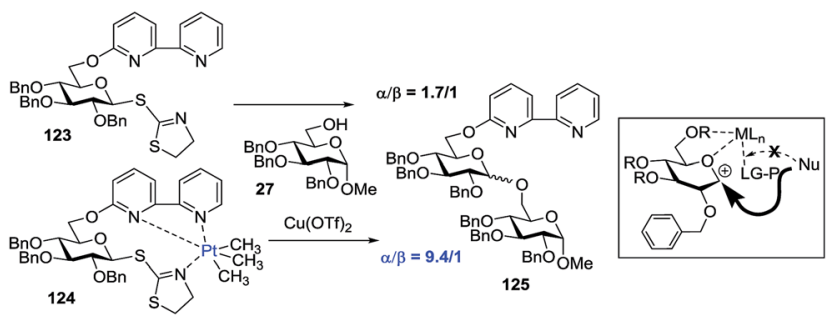

Scheme 17 Effect of metal complexation on the stereoselectivity of glycosylation.

27 in the presence of $\mathrm{Cu}(\mathrm{OTf})_{2}$ gave disaccharide 125 with poor selectivity $(\alpha / \beta=1.7 / 1)$, the complexed glycosyl donor counterpart 124 showed a significant 5-fold increase in 1,2-cis stereoselectivity $(\alpha / \beta=9.4 / 1)$.

\section{F. Other effects and special methods}

High pressure applied to reactions with participating glycosyl donors further enhances 1,2-trans selectivity; ${ }^{\mathbf{1 2 0}}$ when the high pressure conditions were applied to glycosylation with a nonparticipating glycosyl donor, a remarkable increase in the reaction yield was noted with only marginal changes in stereoselectivity. ${ }^{\mathbf{1 2 1}}$ Unfavorable steric interactions, such as "double stereodifferentiation"122 that occur between the glycosyl donor and acceptor in the transition state or other factors or conditions may unexpectedly govern the course and outcome of the glycosylation process.

A number of methods have been developed that do not include a formal glycosylation step. ${ }^{123}$ Typically, these indirect procedures include multistep syntheses and are of lower efficiency than direct glycosylation. Therefore, practical application of these techniques is envisaged for the synthesis of glycosidic linkages that cannot be easily accessed by conventional technologies. O'Doherty developed a well-rounded methodology for palladium(0)-catalyzed glycosylation, wherein carbohydrate chirality centers are installed post-glycosylationally. ${ }^{25 e, 124}$ The de novo asymmetric methodology was applied to the synthesis of mono, di, and oligosaccharides via a palladium-catalyzed reaction. The synthesis of 1,2-cis linkages have not yet been accomplished.

\section{F.1. Intramolecular aglycone delivery (IAD)}

Barresi and Hindsgaul were the first to apply the idea of intramolecular glycosylation, which was used for the synthesis of $\beta$-mannosides. ${ }^{125}$ Subsequently, it was demonstrated that silicon bridge-mediated aglycone delivery provides high yields and excellent stereocontrol. ${ }^{\mathbf{1 2 6}}$ Further improvements emerged with the introduction of the allyl-mediated strategy that affords high yields and complete stereoselectivity in $\alpha$-glucosylation and $\beta$-mannosylation. ${ }^{127}$ More recently Ito and co-workers invented naphthylmethyl ether (NAP)-mediated intramolecular aglycone delivery that generally provides significantly higher yields in comparison to those of traditional approaches. ${ }^{\mathbf{1 2 8}}$

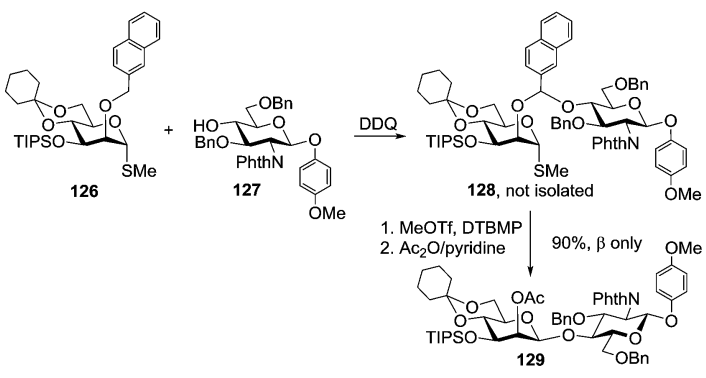

Scheme $18 \quad \beta$-Mannosylation via NAP-tether mediated IAD.

A representative example, the synthesis of disaccharide $\mathbf{1 2 9}$, is depicted in Scheme 18. Thus, when 2-O-NAP-protected thiomethyl glycosyl donor $\mathbf{1 2 6}$ was reacted with acceptor $\mathbf{1 2 7}$ in the presence of DDQ, followed by the removal of the NAP tether and acetylation, disaccharide 129 was obtained in 90\% yield with complete $\beta$-selectivity. The further value of this methodology is that it allows for the stereoselective synthesis of various 1,2-cis linkages, such as $\beta$-Man $p, \beta$-Ara $f$, and $\alpha$-Glc $p .{ }^{129}$

\section{F.2. Supported and tagged synthesis}

The last decade has witnessed dramatic improvements in the area of solid phase-supported oligosaccharide synthesis. ${ }^{\mathbf{1 3 0}}$ Polymer supported synthesis is very attractive because it allows execution of the synthesis of oligosaccharide sequences without the necessity of purifying (and characterizing) the intermediates. Another important advantage of oligosaccharide synthesis on solid phase supports is the ease of excess reagent removal (by filtration). This effort culminated in the automated synthesis by Seeberger, which was the first attempt to conquer the challenge of 1,2-cis glycosidic bond formation using an automated approach. ${ }^{131}$ Careful refinement of the reaction conditions allowed 1,2-cis galactosylation in dichloromethane-ether and a Globo-H sequence was assembled as depicted in Scheme 19. First, glycosyl phosphate donor 130 was linked to the resin 136 via glycosylation using TMSOTf (repeated once) as the promoter, followed by deprotection of the Fmoc substituent with piperidine (repeated twice) to provide a polymer-bound acceptor. The general synthetic protocol consists of repetitive

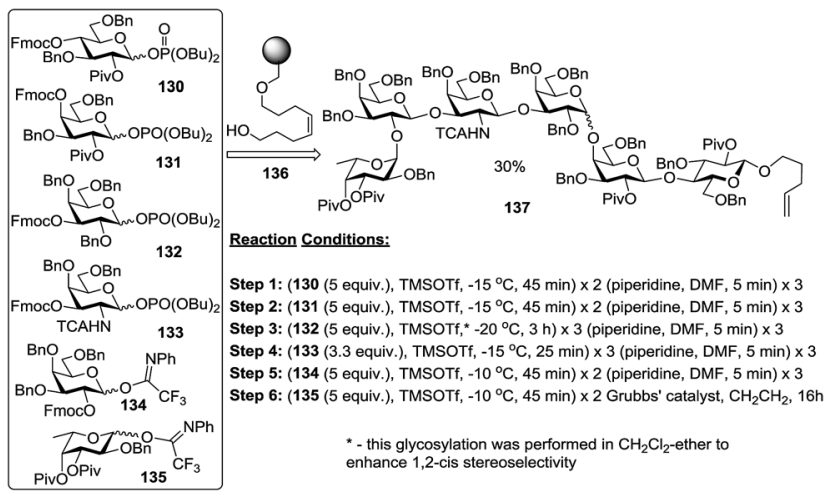

Scheme 19 Automated synthesis of Globo $\mathrm{H}$ hexasaccharide. 
cycles of glycosylation using either glycosyl phosphate (130-133) or PTFAI donors (134 and 135) followed by deprotection with piperidine. The final product 137 was obtained under an atmosphere of ethylene in the presence of Grubbs' catalyst $^{\mathbf{1 3 2}}$ in an overall yield of $30 \%$.

Very recently the same group has reported the total synthesis of an $O$-antigen pentasaccharide repeating unit obtained from pathogenic E. coli. O111. With the synthetic challenge of constructing two unnatural and labile coitose units, the total synthesis was achieved in 21 steps with $1.5 \%$ overall yield. ${ }^{133}$ Boons et al. presented a very elegant synthesis of an $\alpha$-linked oligosaccharide on a polymer support using their recent chiral auxiliary-assisted synthesis of 1,2-cis glycosides. ${ }^{38}$

A promising technique for tagged oligosaccharide synthesis that makes use of an ionic-liquid support has recently emerged. ${ }^{134}$ As with the polymer-supported and fluorous tagsupported syntheses, ${ }^{\mathbf{1 3 5}}$ ionic liquid-supported assembly expedites oligosaccharide synthesis by eliminating the need for chromatographic purification of the intermediates. ${ }^{\mathbf{1 3 4 b , 1 3 6}}$ Differently from insoluble polymer beads, ionic liquid supports allow for homogeneous conditions. This approach is illustrated by the synthesis of trisaccharide 141 (Scheme 20). ${ }^{137}$

In this synthetic strategy, the glycosyl acceptor 139 was grafted onto an ionic liquid support at the C-6 position of the sugar moiety. The resulting tagged glycosyl acceptor 139 was reacted with TCAI donor 138 to afford disaccharide 140 in 89\% yield and high $\alpha$-stereoselectivity. The purification is accomplished by simple washing or liquid-liquid extractions. Disaccharide 140 was then reacted with acceptor 28 , followed by the removal of the ionic liquid tag using $\mathrm{LiOH}-\mathrm{H}_{2} \mathrm{O}$ to afford trisaccharide 141 in $87 \%$ yield.

\section{G. Conclusions and outlook}

Progress in the area of chemical glycosylation has significantly improved our ability to synthesize various glycosidic linkages with impressive yields and stereoselectivity. Can we conclude that we have entirely solved the problem of chemical glycosylation? Unfortunately not, and hopefully this review has introduced the reader to the challenge of chemical glycosylation, a variety of factors, conditions, and driving forces influencing all

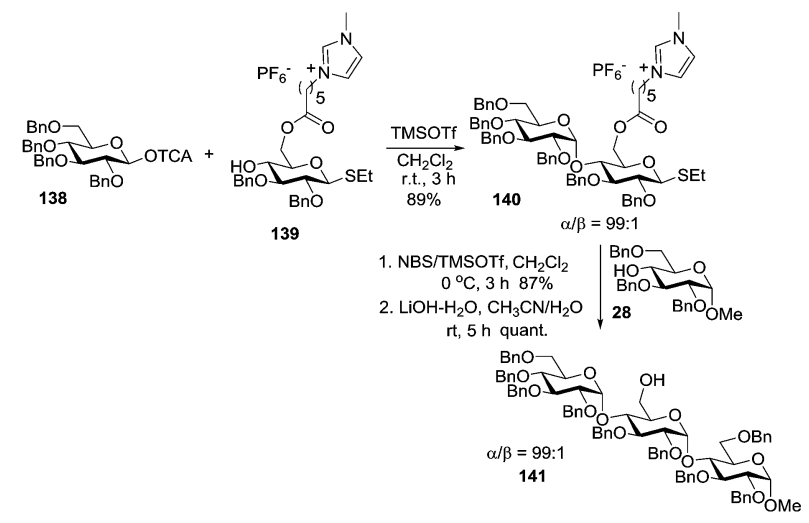

Scheme 20 Glycosylation on an ionic liquid support. aspects of this complex chemical reaction. Hopefully, the reader has obtained the information about specialized methods and strategies employed in modern carbohydrate chemistry.

The authors believe that progress in the development of new coupling methods and efficient strategies for oligosaccharide synthesis will ultimately provide an efficient and trouble-free access to complex saccharides. This goal cannot be achieved without comprehensive knowledge of the glycosylation mechanism and the driving forces of glycosylation and competing side processes. We project that subsequent scientific developments in this field will focus more and more on studying the mechanistic aspects of the glycosylation reaction. As new mechanistic knowledge emerges, further refinement of the reaction conditions and development of new directing protecting groups and even additional anomeric leaving groups may reemerge.

\section{Acknowledgements}

The authors are indebted to the NSF (CHE-1058112) and NIGMS (GM111835) for support of their work on the development of new methods and strategies for stereoselective oligosaccharide synthesis. S.S.N. is indebted to the UM - St. Louis Graduate School for awarding her with the Dissertation Fellowship.

\section{Notes and references}

1 A. Varki, R. D. Cummings, J. D. Esko, H. H. Freeze, C. R. Bertozzi, P. Stanley, G. W. Hart and M. E. Etzler, Essentials of Glycobiology, CSH Laboratory Press, New York, 2nd edn, 2009.

2 H. Cao, J. Hwang and X. Chen, in Opportunity, Challenge and Scope of Natural Products in Medicinal Chemistry, ed. V. K. Tiwari and B. B. Mishra, 2011, pp. 411-431.

3 C. Zhao, M. Li, Y. Luo and W. Wu, Carbohydr. Res., 2006, 341, 485-491.

4 (a) V. C. B. Bittencourt, R. T. Figueiredo, R. B. da Silva, D. S. Mourão-Sá, P. L. Fernandez, G. L. Sassaki, B. Mulloy, M. T. Bozza and E. Barreto-Bergter, J. Biol. Chem., 2006, 281, 22614-22623; (b) L. C. L. Lopes, M. I. D. da Silva, V. C. B. Bittencourt, R. T. Figueiredo, R. Rollin-Pinheiro, G. L. Sassaki, M. T. Bozza, P. A. J. Gorin and E. BarretoBergter, Mycoses, 2011, 54, 28-36.

5 A. O. Tzianabos, A. Pantosti, H. Baumann, J. R. Brisson, H. J. Jennings and D. L. Kasper, J. Biol. Chem., 1992, 267, 18230-18235.

6 J. B. Robbins, C. J. Lee, S. C. Rastogi, G. Schiffman and J. Henrichsen, Infect. Immun., 1979, 26, 1116-1122.

7 C. Jones, Carbohydr. Res., 2005, 340, 1097-1106.

8 Z. Wang, Z. S. Chinoy, S. G. Ambre, W. Peng, R. McBride, R. P. de Vries, J. Glushka, J. C. Paulson and G. J. Boons, Science, 2013, 341, 379-383.

9 (a) G. Ragupathi, F. Koide, P. O. Livingston, Y. S. Cho, A. Endo, Q. Wan, M. K. Spassova, S. J. Keding, J. Allen, O. Ouerfelli, R. M. Wilson and S. J. Danishefsky, J. Am. Chem. Soc., 2006, 128, 2715-2725; (b) Z. Yin and X. Huang, J. Carbohydr. Chem., 2012, 31, 143-186. 
10 (a) L. Goodman, Adv. Carbohydr. Chem. Biochem., 1967, 22, 109-175; (b) T. Nukada, A. Berces, M. Z. Zgierski and D. M. Whitfield, J. Am. Chem. Soc., 1998, 120, 13291-13295.

11 I. Tvaroska and T. Bleha, Adv. Carbohydr. Chem. Biochem., 1989, 47, 45-123.

12 (a) A. V. Demchenko, Curr. Org. Chem., 2003, 7, 35-79; (b) A. V. Demchenko, Synlett, 2003, 1225-1240; (c) A. E. Christina, G. A. van der Marel and J. D. C. Codee, in Modern Synthetic Methods in Carbohydrate Chemistry, ed. D. B. Werz and S. Vidal, Wiley-VCH Verlag GmbH \& Co. KGaA, Weinheim, Germany, 2014, pp. 97-124; (d) S. Crotti and R. Adamo, Curr. Org. Synth., 2013, 10, 501-524.

13 A. F. Bochkov and G. E. Zaikov, Chemistry of the O-glycosidic bond: formation and cleavage, Pergamon Press, Oxford - New York - Toronto - Sydney - Paris - Frankfurt, 1979.

14 A. Varki, Glycobiology, 1993, 3, 97-130.

15 (a) H. Paulsen and O. Lockhoff, Chem. Ber., 1981, 114, 31023114; (b) C. A. A. van Boeckel, T. Beetz and S. F. van Aelst, Tetrahedron, 1984, 40, 4097-4107 and references therein.

16 (a) D. Crich, J. Carbohydr. Chem., 2002, 21, 667-690; (b) E. S. H. El Ashry, N. Rashed and E. S. I. Ibrahim, Curr. Org. Synth., 2005, 2, 175-213.

17 D. Crich and S. Sun, J. Org. Chem., 1996, 61, 4506-4507. 18 D. Crich and M. Smith, Org. Lett., 2000, 2, 4067-4069.

19 (a) D. Crich, J. Org. Chem., 2011, 76, 9193-9209; (b) D. Crich, Acc. Chem. Res., 2010, 43, 1144-1153.

20 (a) M. Gelin, V. Ferrieres and D. Plusquellec, Eur. J. Org. Chem., 2000, 1423-1431; (b) T. L. Lowary, J. Carbohydr. Chem., 2002, 21, 691-722.

21 (a) R. R. Gadikota, C. S. Callam and T. L. Lowary, Org. Lett., 2001, 3, 607-610; (b) Y. Bai and T. L. Lowary, J. Org. Chem., 2006, 71, 9658-9671.

22 (a) X. Zhu, S. Kawatkar, Y. Rao and G. J. Boons, J. Am. Chem. Soc., 2006, 128, 11948-11957; (b) D. Crich, C. M. Pedersen, A. A. Bowers and D. J. Wink, J. Org. Chem., 2007, 72, 15531565.

23 A. Ishiwata, H. Akao and Y. Ito, Org. Lett., 2006, 8, 55255528.

24 (a) A. Veyrieres, in Carbohydrates in Chemistry and Biology, ed. B. Ernst, G. W. Hart and P. Sinay, Wiley-VCH, Weinheim, New York, 2000, vol. 1, pp. 367-406; (b) C. H. Marzabadi and R. W. Franck, Tetrahedron, 2000, 56, 8385-8417.

25 (a) S. Adhikari, K. N. Baryal, D. Zhu, X. Li and J. Zhu, ACS Catal., 2013, 3, 57-60; (b) G. Diaz, A. Ponzinibbio and R. D. Bravo, Top. Catal., 2012, 55, 644-648; (c) W. J. Morris and M. D. Shair, Org. Lett., 2009, 11, 9-12; (d) Y.-S. Lu, Q. Li, L.-H. Zhang and X.-S. Ye, Org. Lett., 2008, 10, 3445-3448; (e) M. Zhou and G. A. O'Doherty, J. Org. Chem., 2007, 72, 2485-2493; (f) J. M. Nogueira, J. P. Issa, A.-H. A. Chu, J. A. Sisel, R. S. Schum and C. S. Bennett, Eur. J. Org. Chem., 2012, 2012, 4927-4930; (g) J.-H. Ruei, P. Venukumar, A. B. Ingle and K.-K. T. Mong, Chem. Commun., 2015, 51, 5394-5397.

26 (a) G. J. Boons and A. V. Demchenko, Chem. Rev., 2000, 100, 4539-4565; (b) D. K. Ress and R. J. Linhardt, Curr. Org. Synth., 2004, 1, 31-46; (c) K. Ikeda, M. Sato and
Y. Torisawa, Curr. Med. Chem., 2004, 3, 339-350; (d) C. De Meo, ACS Symp. Ser., 2007, 960, 118-131; (e) C. De Meo, G. J. Boons and A. V. Demchenko, in Comprehensive Glycoscience - From Chemistry to Systems Biology, ed. J. P. Kamerling, Elsevier, 2007; (f) S. Muthana, H. Cao and X. Chen, Curr. Opin. Chem. Biol., 2009, 13, 573-581.

27 (a) H. Tanaka, Y. Nishiura and T. Takahashi, J. Am. Chem. Soc., 2006, 128, 7124-7125; (b) M. D. Farris and C. De Meo, Tetrahedron Lett., 2007, 48, 1225-1227; (c) D. Crich and W. Li, J. Org. Chem., 2007, 72, 2387-2391.

28 X. Zhu and R. R. Schmidt, Angew. Chem., Int. Ed., 2009, 48, 1900-1934.

29 W. Zhong and G.-J. Boons, in Handbook of Chemical Glycosylation, ed. A. V. Demchenko, Wiley-VCH, Weinheim, Germany, 2008, pp. 261-303.

30 R. U. Lemieux, K. B. Hendriks, R. V. Stick and K. James, J. Am. Chem. Soc., 1975, 97, 4056-4062 and references therein.

31 S. Kaeothip, J. P. Yasomanee and A. V. Demchenko, J. Org. Chem., 2012, 77, 291-299.

32 N. K. Kochetkov, E. M. Klimov, N. N. Malysheva and A. V. Demchenko, Carbohydr. Res., 1991, 212, 77-91.

33 B. Fraser-Reid, K. N. Jayaprakash, J. C. López, A. M. Gómez and C. Uriel, in ACS Symp. Ser. (Frontiers in Modern Carbohydrate Chemistry), ed. A. V. Demchenko, Oxford Univ. Press, 2007, vol. 960, pp. 91-117.

34 (a) S. K. Mamidyala and M. G. Finn, J. Org. Chem., 2009, 74, 8417-8420; (b) B. Meng, Z. Zhu and D. C. Baker, Org. Biomol. Chem., 2014, 12, 5182-5191.

35 (a) J. T. Smoot and A. V. Demchenko, J. Org. Chem., 2008, 73, 8838-8850; (b) J. T. Smoot, P. Pornsuriyasak and A. V. Demchenko, Angew. Chem., Int. Ed., 2005, 44, 71237126.

36 J. H. Kim, H. Yang and G. J. Boons, Angew. Chem., Int. Ed., 2005, 44, 947-949.

37 (a) J. H. Kim, H. Yang, J. Park and G. J. Boons, J. Am. Chem. Soc., 2005, 127, 12090-12097; (b) T. J. Boltje, J.-H. Kim, J. Park and G.-J. Boons, Org. Lett., 2011, 13, 284-287.

38 T. J. Boltje, J. H. Kim, J. Park and G. J. Boons, Nat. Chem., 2010, 2, 552-557.

39 T. Fang, K.-F. Mo and G.-J. Boons, J. Am. Chem. Soc., 2012, 134, 7545-7552.

40 M. A. Fascione, S. J. Adshead, S. A. Stalford, C. A. Kilner, A. G. Leach and W. B. Turnbull, Chem. Commun., 2009, 5841-5843.

41 M. A. Fascione, N. J. Webb, C. A. Kilner, S. L. Warriner and W. B. Turnbull, Carbohydr. Res., 2012, 348, 6-13.

42 (a) T. Ishikawa and H. G. Fletcher, J. Org. Chem., 1969, 34, 563-571; (b) R. Eby and C. Schuerch, Carbohydr. Res., 1974, 34, 79-90 and references therein; (c) T. Mukaiyama, M. Suenaga, H. Chiba and H. Jona, Chem. Lett., 2002, 56-57.

43 (a) A. V. Demchenko, E. Rousson and G. J. Boons, Tetrahedron Lett., 1999, 40, 6523-6526; (b) M. Takatani, I. Matsuo and Y. Ito, Carbohydr. Res., 2003, 338, 1073-1081. 44 (a) E. J. Corey and P. Carpino, J. Am. Chem. Soc., 1989, 111, 5472-5473; (b) A. G. Gerbst, N. E. Ustuzhanina, A. A. Grachev, D. E. Tsvetkov, E. A. Khatuntseva and N. E. Nifant'ev, Mendeleev Commun., 1999, 114-116. 
45 T. Yamanoi, K. Nakamura, H. Takeyama, K. Yanagihara and T. Inazu, Bull. Chem. Soc. Jpn., 1994, 67, 1359-1366.

46 C. De Meo, M. N. Kamat and A. V. Demchenko, Eur. J. Org. Chem., 2005, 706-711.

47 N. Ustyuzhanina, B. Komarova, N. Zlotina, V. Krylov, A. G. Gerbst, Y. Tsvetkov and N. E. Nifantiev, Synlett, 2006, 921-923.

48 J. Y. Baek, B. Y. Lee, M. G. Jo and K. S. Kim, J. Am. Chem. Soc., 2009, 131, 17705-17713.

49 B. S. Komarova, M. V. Orekhova, Y. E. Tsvetkov and N. E. Nifantiev, Carbohydr. Res., 2014, 384, 70-86.

50 C. A. A. van Boeckel and T. Beetz, Recl. Trav. Chim. Pays-Bas, 1985, 104, 171-173.

51 J. Kalikanda and Z. Li, J. Org. Chem., 2011, 76, 5207-5218. 52 G. Ngoje and Z. Li, Org. Biomol. Chem., 2013, 11, 1879-1886.

53 D. Crich, W. Cai and Z. Dai, J. Org. Chem., 2000, 65, 12911297.

54 D. Crich, P. Jayalath and T. K. Hutton, J. Org. Chem., 2006, 71, 3064-3070.

55 M. M. Zulueta, S. Y. Lin, Y. T. Lin, C. J. Huang, C. C. Wang, C. C. Ku, Z. Shi, C. L. Chyan, D. Irene, L. H. Lim, T. I. Tsai, Y. P. Hu, S. D. Arco, C. H. Wong and S. C. Hung, J. Am. Chem. Soc., 2012, 134, 8988-8995.

$56(a)$ M. T. C. Walvoort, G. Lodder, J. Mazurek, H. S. Overkleeft, J. D. C. Codee and G. A. van der Marel, J. Am. Chem. Soc., 2009, 131, 12080-12081; (b) M. T. C. Walvoort, G. Lodder, H. S. Overkleeft, J. D. C. Codee and G. A. van der Marel, J. Org. Chem., 2010, 75, 7990-8002.

57 J. P. Yasomanee and A. V. Demchenko, J. Am. Chem. Soc., 2012, 134, 20097-20102.

58 S. G. Pistorio, J. P. Yasomanee and A. V. Demchenko, Org. Lett., 2014, 16, 716-719.

59 J. P. Yasomanee and A. V. Demchenko, Angew. Chem., Int. Ed., 2014, 53, 10453-10456.

60 J. P. Yasomanee and A. V. Demchenko, Chem.-Eur. J., 2015, 21, DOI: $10.1002 /$ chem.201406589.

61 Q.-W. Liu, H.-C. Bin and J.-S. Yang, Org. Lett., 2013, 15, 3974-3977.

62 (a) D. Crich and W. Cai, J. Org. Chem., 1999, 64, 4926-4930; (b) D. Crich and N. S. Chandrasekera, Angew. Chem., Int. Ed., 2004, 43, 5386-5389 and references therein.

63 M. Huang, G. E. Garrett, N. Birlirakis, L. Bohe, D. A. Pratt and D. Crich, Nat. Chem., 2012, 4, 663-667.

64 (a) D. Crich and S. Sun, J. Org. Chem., 1997, 62, 1198-1199; (b) D. Crich and S. Sun, J. Am. Chem. Soc., 1997, 119, 1121711223.

65 D. Crich and S. Sun, J. Am. Chem. Soc., 1998, 120, 435-436. 66 R. Weingart and R. R. Schmidt, Tetrahedron Lett., 2000, 41, 8753-8758.

67 K. S. Kim, J. H. Kim, Y. J. Lee, Y. J. Lee and J. Park, J. Am. Chem. Soc., 2001, 123, 8477-8481.

68 J. D. C. Codee, L. H. Hossain and P. H. Seeberger, Org. Lett., 2005, 7, 3251-3254.

69 J. Y. Baek, T. J. Choi, H. B. Jeon and K. S. Kim, Angew. Chem., Int. Ed., 2006, 45, 7436-7440.
70 (a) K. S. Kim, Y. J. Lee, H. Y. Kim, S. S. Kang and S. Y. Kwon, Org. Biomol. Chem., 2004, 2, 2408-2410; (b) K. S. Kim, D. B. Fulse, J. Y. Baek, B. Y. Lee and H. B. Jeon, J. Am. Chem. Soc., 2008, 130, 8537-8547.

71 M. H. El-Badr, D. Willenbring, D. J. Tantillo and J. GervayHague, J. Org. Chem., 2007, 72, 4663-4672.

72 B. Fraser-Reid, Z. Wu, C. W. Andrews and E. Skowronski, J. Am. Chem. Soc., 1991, 113, 1434-1435.

73 H. H. Jensen, L. U. Nordstrom and M. Bols, J. Am. Chem. Soc., 2004, 126, 9205-9213.

74 D. Crich, A. Banerjee and Q. Yao, J. Am. Chem. Soc., 2004, 126, 14930-14934.

75 C. Brand, M. Granitzka, D. Stalke and D. B. Werz, Chem. Commun., 2011, 47, 10782-10784.

76 (a) K. Benakli, C. Zha and R. J. Kerns, J. Am. Chem. Soc., 2001, 123, 9461-9462; (b) R. J. Kerns, C. Zha, K. Benakli and Y.-Z. Liang, Tetrahedron Lett., 2003, 44, 8069-8072.

77 (a) P. Wei and R. J. Kerns, J. Org. Chem., 2005, 70, 41954198; (b) P. Wei and R. J. Kerns, Tetrahedron Lett., 2005, 46, 6901-6905.

78 M. Boysen, E. Gemma, M. Lahmann and S. Oscarson, Chem. Commun., 2005, 24, 3044-3046.

79 (a) Y. Geng, L.-H. Zhang and X.-S. Ye, Tetrahedron, 2008, 64, 4949-4958; (b) Y. Geng, L.-H. Zhang and X.-S. Ye, Chem. Commun., 2008, 597-599; (c) L. Yang and X. S. Ye, Carbohydr. Res., 2010, 345, 1713-1721.

80 (a) J. D. M. Olsson, L. Eriksson, M. Lahmann and S. Oscarson, J. Org. Chem., 2008, 73, 7181-7188; (b) H. Satoh, S. Manabe, Y. Ito, H. P. Lüthi, T. Laino and J. Hutter, J. Am. Chem. Soc., 2011, 133, 5610-5619.

81 (a) S. Manabe, K. Ishii and Y. Ito, J. Am. Chem. Soc., 2006, 128, 10666-10667; (b) S. Manabe, K. Ishii and Y. Ito, Eur. J. Org. Chem., 2011, 497-516.

82 D. Crich and J. Picione, Org. Lett., 2003, 5, 781-784.

83 D. Crich and P. Jayalath, J. Org. Chem., 2005, 70, 7252-7259.

84 Y. Geng, Q. Qin and X.-S. Ye, J. Org. Chem., 2012, 77, 52555270.

85 (a) A. Imamura, H. Ando, H. Ishida and M. Kiso, Org. Lett., 2005, 7, 4415-4418; (b) A. Imamura, H. Ando, H. Ishida and M. Kiso, Heterocycles, 2008, 76, 883-908; (c) A. Imamura, H. Ando, S. Korogi, G. Tanabe, O. Muraoka, H. Ishida and M. Kiso, Tetrahedron Lett., 2003, 44, 6725-6728.

86 A. Hara, A. Imamura, H. Ando, H. Ishida and M. Kiso, Molecules, 2014, 19, 414-437.

87 (a) P. Sinay, Pure Appl. Chem., 1978, 50, 1437-1452; (b) H. Paulsen, Angew. Chem., Int. Ed. Engl., 1982, 21, 155173; (c) L. G. Green and S. V. Ley, in Carbohydrates in Chemistry and Biology, ed. B. Ernst, G. W. Hart and P. Sinay, Wiley-VCH, Weinheim, New York, 2000, vol. 1, pp. 427-448.

88 S. Kaeothip, S. J. Akins and A. V. Demchenko, Carbohydr. Res., 2010, 345, 2146-2150.

89 T. Kimura, M. Sekine, D. Takahashi and K. Toshima, Angew. Chem., Int. Ed., 2013, 52, 12131-12134.

90 (a) F. Andersson, P. Fugedi, P. J. Garegg and M. Nashed, Tetrahedron Lett., 1986, 27, 3919-3922; (b) S. Manabe, Y. Ito and T. Ogawa, Synlett, 1998, 628-630. 
91 (a) R. R. Schmidt and E. Rucker, Tetrahedron Lett., 1980, 21, 1421-1424; (b) H. Dohi, Y. Nishida, H. Tanaka and K. Kobayashi, Synlett, 2001, 1446-1448.

92 A. Ishiwata, Y. Munemura and Y. Ito, Tetrahedron, 2008, 64, 92-102.

93 G. Wulff and G. Rohle, Angew. Chem., Int. Ed. Engl., 1974, 13, 157-170.

94 A. Demchenko, T. Stauch and G. J. Boons, Synlett, 1997, 818-820.

95 C. S. Chao, C. Y. Lin, S. Mulani, W. C. Hung and K. K. Mong, Chem.-Eur. J., 2011, 17, 12193-12202.

96 H. Knoben, U. Schuluter and H. Redlich, Carbohydr. Res., 2004, 339, 2821-2833.

97 K. Jayakanthan and Y. D. Vankar, Carbohydr. Res., 2005, 340, 2688-2692.

98 T. Shirahata, J.-i. Matsuo, S. Teruya, N. Hirata, T. Kurimoto, N. Akimoto, T. Sunazuka, E. Kaji and S. Omura, Carbohydr. Res., 2010, 345, 740-749.

99 G. Wasonga, Y. Zeng and X. Huang, Sci. China: Chem., 2011, 54, 66-73.

100 H. Satoh, H. S. Hansen, S. Manabe, W. F. van Gunsteren and P. H. Hunenberger, J. Chem. Theory Comput., 2010, 6, 1783-1797.

101 C.-Y. I. Liu, S. Mulani and K.-K. T. Mong, Adv. Synth. Catal., 2012, 354, 3299-3310.

102 (a) W. Koenigs and E. Knorr, Ber. Dtsch. Chem. Ges., 1901, 34, 957-981; (b) K. Igarashi, Adv. Carbohydr. Chem. Biochem., 1977, 34, 243-283.

103 G. Zemplen and A. Gerecs, Ber. Dtsch. Chem. Ges., 1930, 63, 2720-2729.

104 B. Helferich and K. F. Wedemeyer, Justus Liebigs Ann. Chem., 1949, 563, 139-145.

105 (a) B. Helferich and J. Zirner, Chem. Ber., 1962, 95, 26042611; (b) R. B. Conrow and S. Bernstein, J. Org. Chem., 1971, 36, 863-870.

106 M. J. Hadd and J. Gervay, J. Carbohydr. Res., 1999, 320, 61. 107 S. S. Kulkarni and J. Gervay-Hague in Handbook of Chemical Glycosylation, ed. A. V. Demchenko, Wiley-VCH, Weinheim, Germany, 2008, p. 59.

108 G. H. Veeneman and J. H. van Boom, Tetrahedron Lett., 1990, 31, 275-278.

109 M. J. McKay and H. M. Nguyen, ACS Catal., 2012, 2, 15631595.

110 (a) J. Yang, C. Cooper-Vanosdell, E. A. Mensah and H. M. Nguyen, J. Org. Chem., 2008, 73, 794-800; (b) E. A. Mensah, J. M. Azzarelli and H. M. Nguyen, J. Org. Chem., 2009, 74, 1650-1657.

111 (a) E. A. Mensah and H. M. Nguyen, J. Am. Chem. Soc., 2009, 131, 8778-8780; (b) E. A. Mensah, F. Yu and H. M. Nguyen, J. Am. Chem. Soc., 2010, 132, 14288-14302.

112 (a) S. Hotha and S. Kashyap, J. Am. Chem. Soc., 2006, 128, 9620-9621; (b) G. Sureshkumar and S. Hotha, Tetrahedron Lett., 2007, 48, 6564-6568; (c) A. S. K. Hashmi, Chem. Rev., 2007, 107, 3180-3211; (d) Y. Li, X. Yang, Y. Liu, C. Zhu, Y. Yang and B. Yu, Chem.-Eur. J., 2010, 16, 1871-1882; (e) Y. Ma, Z. Li, H. Shi, J. Zhang and B. Yu, J. Org. Chem., 2011, 76, 9748-9756.
113 S. E. Reisman, A. G. Doyle and E. N. Jacobsen, J. Am. Chem. Soc., 2008, 130, 7198-7199.

114 E. I. Balmond, D. M. Coe, M. C. Galan and E. M. McGarrigle, Angew. Chem., Int. Ed., 2012, 51, 9152-9155.

115 Y. Geng, A. Kumar, H. M. Faidallah, H. A. Albar, I. A. Mhkalid and R. R. Schmidt, Angew. Chem., Int. Ed., 2013, 52, 10089-10092.

116 A.-H. A. Chu, S. H. Nguyen, J. A. Sisel, A. Minciunescu and C. S. Bennett, Org. Lett., 2013, 15, 2566-2569.

117 (a) T. Mukaiyama and K. Matsubara, Chem. Lett., 1992, 1041-1044; (b) K. Fukase, A. Hasuoka, I. Kinoshita, Y. Aoki and S. Kusumoto, Tetrahedron, 1995, 51, 4923-4932.

118 S. J. Hasty, S. C. Ranade and A. V. Demchenko, Rep. Org. Chem., 2014, 4, 1-10.

119 P. Pornsuriyasak, C. Vetter, S. Kaeothip, M. Kovermann, J. Balbach, D. Steinborn and A. V. Demchenko, Chem. Commun., 2009, 6379-6381.

120 E. M. Klimov, N. N. Malysheva, A. V. Demchenko, Z. G. Makarova, V. M. Zhulin and N. K. Kochetkov, Dokl. Akad. Nauk, 1989, 309, 110-114 and references therein.

121 M. Sasaki, Y. Gama, M. Yasumoto and Y. Ishigami, Tetrahedron Lett., 1990, 31, 6549-6552.

122 N. M. Spijker and C. A. A. van Boeckel, Angew. Chem., Int. Ed. Engl., 1991, 30, 180-183.

123 (a) F. Paquet and P. Sinay, Tetrahedron Lett., 1984, 25, 30713074; (b) H. Ohtake, N. Ichiba and S. Ikegami, J. Org. Chem., 2000, 65, 8171-8179.

124 (a) R. S. Babu, M. Zhou and G. A. O'Doherty, J. Am. Chem. Soc., 2004, 126, 3428-3429; (b) H. Guo and G. A. O'Doherty, J. Org. Chem., 2008, 73, 5211-5220; (c) M. Zhou and G. A. O'Doherty, Curr. Top. Med. Chem., 2008, 8, 114-125.

125 F. Barresi and O. Hindsgaul, J. Am. Chem. Soc., 1991, 113, 9376-9377.

126 (a) G. Stork and G. Kim, J. Am. Chem. Soc., 1992, 114, 10871088; (b) M. Bols, J. Chem. Soc., Chem. Commun., 1992, 913914.

127 C. M. P. Seward, I. Cumpstey, M. Aloui, S. C. Ennis, A. J. Redgrave and A. J. Fairbanks, Chem. Commun., 2000, 1409-1410.

128 A. Ishiwata, Y. Munemura and Y. Ito, Eur. J. Org. Chem., 2008, 4250-4263.

129 (a) A. Ishiwata, Y. J. Lee and Y. Ito, Org. Biomol. Chem., 2010, 8, 3596-3608; (b) A. Ishiwata, S. Kaeothip, Y. Takeda and Y. Ito, Angew. Chem., Int. Ed., 2014, 53, 9812-9816.

130 P. H. Seeberger, Chem. Soc. Rev., 2008, 37, 19-28.

131 D. B. Werz, B. Castagner and P. H. Seeberger, J. Am. Chem. Soc., 2007, 129, 2770-2771.

132 R. H. Grubbs, S. J. Miller and G. C. Fu, Acc. Chem. Res., 1995, 28, 446-452.

133 O. Calin, S. Eller, H. S. Hahm and P. H. Seeberger, Chem.Eur. J., 2013, 19, 3995-4002.

134 (a) C. Huo and T. H. Chan, Chem. Soc. Rev., 2010, 39, 29773006; (b) A. K. Pathak, C. K. Yerneni, Z. Young and V. Pathak, Org. Lett., 2008, 10, 145-148.

135 (a) T. Miura, K. Goto, H. Waragai, H. Matsumoto, Y. Hirose, M. Ohmae, H. Ishida, A. Satoh and T. Inazu, J. Org. Chem., 
2004, 69, 5348-5353; (b) F. A. Jaipuri and N. L. Pohl, Org. Biomol. Chem., 2008, 6, 2686-2691; (c) L. Liu and N. L. B. Pohl, Org. Lett., 2011, 13, 1824-1827.

136 (a) K. Sasaki, H. Nagai, S. Matsumura and K. Toshima, Tetrahedron Lett., 2003, 44, 5605-5608; (b) K. Sasaki, S. Matsumura and K. Toshima, Tetrahedron Lett., 2004, 45, 7043-7047; (c) A. Rencurosi, L. Lay, G. Russo, E. Caneva and L. Poletti, J. Org. Chem., 2005, 70, 77657768; (d) J.-Y. Huang, M. Lei and Y.-G. Wang, Tetrahedron
Lett., 2006, 47, 3047-3050; (e) A. Rencurosi, L. Lay, G. Russo, E. Caneva and L. Poletti, Carbohydr. Res., 2006, 341, 903-908; (f) M. C. Galan and A. P. Corfield, Biochem. Soc. Trans., 2010, 38, 1368-1373; $(g)$ M. C. Galan, K. Jouvin and D. Alvarez-Dorta, Carbohydr. Res., 2010, 345, 45-49.

137 M. Pépin, M. Hubert-Roux, C. Martin, F. Guillen, C. Lange and G. Gouhier, Eur. J. Org. Chem., 2010, 6366-6371. 